\title{
1 Chromatin profiling reveals reorganization of lysine specific 2 demethylase 1 by an oncogenic fusion protein
}

3 Emily R. Theisen ${ }^{1 *}$, Julia Selich-Anderson ${ }^{1}$, Kyle R. Miller ${ }^{1}$, Jason M. Tanner ${ }^{2}$, Cenny Taslim ${ }^{1}$, Kathleen I.

$4 \quad$ Pishas $^{1,3}$, Sunil Sharma ${ }^{4}$, Stephen L. Lessnick ${ }^{1,5}$

$5 \quad{ }^{1}$ Center for Childhood Cancer and Blood Diseases, The Abigail Wexner Research Institute at Nationwide

6 Children's Hospital, Columbus, $\mathrm{OH}, 43205$, USA

72 Department of Biochemistry, University of Utah School of Medicine, Salt Lake City, UT, 84132, USA

$8 \quad{ }^{3}$ Peter MacCallum Cancer Centre, Melbourne, VIC, 300, AUS

$9 \quad{ }^{4}$ Applied Cancer Research and Drug Discovery, Translational Genomics Research Institute (TGen),

10 Phoenix, AX, 85004 USA

115 Division of Pediatric Hematology/Oncology/Blood and Marrow Transplant, The Ohio State University,

12 Columbus, $\mathrm{OH}, 43210, \mathrm{USA}$

13 * To whom correspondence should be addressed. Tel: +1 (614) 355 2995; Fax: +1 (614) 355 2927; Email:

14 emily.theisen@nationwidechildrens.org ORCID iD: https://orcid.org/0000-0003-2923-1198

15 Keywords: Chromatin, LSD1, Epigenetics, EWS/FLI, Super-enhancers, Ewing sarcoma,

16 Logistics: This manuscript contains 6 figures, 14 supplementary figures, 21 supplementary tables, and 1766 references. 


\section{ABSTRACT:}

20 Pediatric cancers commonly harbor quiet mutational landscapes and are instead characterized by single

21 driver events such as the mutation of critical chromatin regulators, expression of oncohistones, or

22 expression of oncogenic fusion proteins. These events ultimately promote malignancy through disruption

23 of normal gene regulation and development. The driver protein in Ewing sarcoma, EWS/FLI, is an

24 oncogenic fusion and transcription factor that reshapes the enhancer landscape, resulting in widespread

25 transcriptional dysregulation. Lysine-specific demethylase 1 (LSD1) is a critical functional partner for

$26 \mathrm{EWS/FLI}$ as inhibition of LSD1 reverses the transcriptional activity of EWS/FLI. However, how LSD1

27 participates in fusion-directed epigenomic regulation and aberrant gene activation is unknown. We now

28 show EWS/FLI causes dynamic rearrangement of LSD1 and we uncover a role for LSD1 in gene

29 activation through colocalization at EWS/FLI binding sites throughout the genome. LSD1 is integral to the

30 establishment of Ewing sarcoma super-enhancers at GGAA-microsatellites, which ubiquitously overlap

31 non-microsatellite loci bound by EWS/FLI. Together, we show that EWS/FLI induces widespread changes

32 to LSD1 distribution in a process that impacts the enhancer landscape throughout the genome. 


\section{INTRODUCTION}

Ewing sarcoma is an aggressive bone-associated malignancy characterized by the expression of a translocation-derived fusion oncoprotein, most commonly EWS/FLI. ${ }^{1-4}$ The $\mathrm{N}$-terminal portion of the protein is derived from the EWSR1 gene and comprises a low-complexity intrinsically disordered domain which recruits transcriptional co-regulators. ${ }^{5-9}$ The C-terminal FLI portion of the protein is derived from the FLI1 gene, which encodes an ETS-family transcription factor. ${ }^{2}$ EWS/FLI contains the ETS DNA-binding domain (DBD) of FLI and functions as an aberrant transcription factor and chromatin regulator, driving global changes in the epigenetic landscape and gene expression, leading to oncogenesis. ${ }^{5,8-11}$ affinity. ${ }^{12}$ Additionally, the disordered EWS domain confers novel DNA binding properties to the FLI DBD, such that EWS/FLI preferentially binds stretches of repetitive elements with greater than 7 GGAA motifs, called GGAA-microsatellites (GGAA- $\mu$ sats). ${ }^{12-14}$ Binding of EWS/FLI to GGAA- $\mu$ sats often results in aberrant activation of nearby genes. $5,8,13$ This occurs through EWS-mediated recruitment of transcriptional and chromatin regulators, like RNA polymerase $\mathrm{II}^{15}$ and BAF complexes ${ }^{5}$, and de novo assembly of enhancers. ${ }^{5,8}$ Some GGAA- $\mu$ sats are associated with gene repression, through mechanisms not well understood. ${ }^{16}$ The factors which determine whether an EWS/FLI target is activated or repressed, at both high affinity (HA) sites and GGAA- $\mu$ sats, are poorly defined.

Disrupting EWS/FLI-mediated gene regulation through direct targeting of EWS/FLI is not yet clinically feasible. As an alternative approach, we previously demonstrated that treatment with the lysine-specific demethylase 1 (LSD1) inhibitor SP2509 reverses the transcriptional activity of EWS/FLI, and the related EWS/ERG fusion, impairing tumor cell growth and viability. ${ }^{17}$ Prior studies suggested that LSD1 was recruited to EWS/FLI-repressed genes as part of the NURD-LSD1 complex which interacts with the EWS domain ${ }^{9}$. Having also unexpectedly found that pharmacological blockade of LSD1 disrupts EWS/FLImediated gene activation, we predicted that LSD1 recruitment by EWS/FLI is required for chromatin regulation at upregulated targets throughout the genome. Thus, the transcriptional consequences of LSD1 inhibition would recapitulate those of EWS/FLI depletion. residues. ${ }^{18}$ The flavin adenine dinucleotide (FAD) cofactor-mediated chemistry limits LSD1 to demethylation of mono- and dimethylated lysines. ${ }^{18}$ Histone $\mathrm{H} 3$ lysine $4(\mathrm{H} 3 \mathrm{~K} 4)$ is the main substrate for $\mathrm{LSD}^{18}{ }^{18}$, though LSD1-mediated demethylation of histone $\mathrm{H} 3$ lysine $9(\mathrm{H} 3 \mathrm{~K} 9)^{19}$ and non-histone proteins, such as $\mathrm{p5} 3^{20}$ and DNMT1 ${ }^{21}$, have been reported. LSD1 lacks a DNA-binding domain, and depends upon interacting with other proteins, commonly RCOR1 (CoREST) and histone deacetylases (HDACs), for recruitment to nucleosomes targeted for demethylation. ${ }^{22}$ LSD1 is essential for stem cell function, enhancer decommissioning during differentiation, and transcriptional regulation through modulation of 
69 enhancer silencing and transcriptional regulation ${ }^{24-26}$, and overexpression of LSD1 is reported in a wide

70 variety of hematological and solid malignancies ${ }^{27-31}$, including Ewing sarcoma. ${ }^{32,33}$ Elevated expression

71 correlates with aggressive tumor biology and poor prognosis. $30,34,35$

72 Given that the clinical analog of SP2509, seclidemstat, is now undergoing clinical investigation in Ewing

73 sarcoma (NCT03600649), we wanted to decipher the functional relationship between EWS/FLI and

74 LSD1. In particular, addressing the role for LSD1 in EWS/FLI-mediated gene activation, whether LSD1

75 contributes to de novo enhancer formation, and how EWS/FLI impacts LSD1 genomic localization. In this

76 study we used genomic methods in multiple Ewing sarcoma cell lines, as well as in a specific cell line,

77 A673, either with wildtype expression of EWS/FLI, with EWS/FLI knocked down as a model for a Ewing

78 sarcoma precursor cell, or with EWS/FLI depletion rescued with ectopic expression of the wildtype fusion.

79 By pairing these studies with our previously published transcriptomic data ${ }^{36}$, we evaluated how EWS/FLI

80 impacts LSD1 function in Ewing sarcoma. 


\section{EWS/FLI and LSD1 colocalize throughout the genome}

Previous investigation of LSD1 inhibition in Ewing sarcoma, both pharmacological blockade ${ }^{17}$ and RNAimediated depletion ${ }^{34}$, suggested that the LSD1 function is critical for EWS/FLI-mediated gene regulation. We therefore used genomic localization studies to ask whether LSD1 colocalized with EWS/FLI at both activated and repressed targets in Ewing sarcoma cells. In A673 cells, we detected 42673 EWS/FLI peaks and 15202 LSD1 peaks. 12058 LSD1 peaks $(79.3 \%, p=0)$ were colocalized with EWS/FLI (Figure 1A-C). Overall LSD1 genomic distribution (Figure 1D) was similar to LSD1 distribution when colocalized with EWS/FLI (Supplementary Figure 1A), with a majority of peaks residing in the promoter, intronic, or intergenic regions.

These patterns of significant EWS/FLI-LSD1 overlap and LSD1 distribution were consistently observed across additional Ewing sarcoma cell lines: EWS-502, SK-N-MC, and TC-71 (Supplementary Figure 1BG). We further identified 10300 common EWS/FLI peaks and 6470 common LSD1 peaks that were present in all cell lines (Supplementary Figure 2A-B). Of these 6470 LSD1 peaks, $3973(61.4 \%, p=0)$ showed colocalization with EWS/FLI in all of the tested cell lines, and these displayed a stronger promoter-proximal distribution (Figures 1E, Supplementary Figure 2C-D). Given the large number of EWS/FLI peaks detected here, likely due to the sensitive methodology used for the localization analysis, we re-analyzed the EWS/FLI-LSD1 overlap and distribution in all cell lines using only those peaks with > 8 -fold-change in enrichment over background. The resulting overlap and distribution analyses were similar as those described above (Supplementary Figures 3A-E, 4A-E). This set of peaks meeting the higher stringency cutoff was used for all further analyses described below.

Prior studies demonstrated that blockade of LSD1 with the reversible LSD1 inhibitor, SP2509, impaired both EWS/FLI-mediated activation and repression. ${ }^{17}$ In light of this finding we note that LSD1 coincided with EWS/FLI peaks at both activated and repressed target genes in A673 cells (Figure 1B-C, Supplementary Figure 5A-B), suggesting a functional relationship. This was consistently observed in all the assayed cell lines (Supplementary Figure 5C-E). To further explore the function of EWS/FLI-LSD1 colocalization in gene regulation, we next used Gene Set Enrichment Analysis (GSEA) ${ }^{37}$ to evaluate the functional relationship of genes near EWS/FLI-LSD1 co-peaks with either EWS/FLI- or LSD1-mediated gene regulation, previously defined using RNAi-mediated depletion. Genes with EWS/FLI and LSD1 colocalized within $1 \mathrm{~kb}$ of transcription start site (TSS) were functionally associated with EWS/FLImediated gene activation in all tested cell lines (Supplementary Figure 6A-C). We also found an association between EWS/FLI-LSD1 colocalization and LSD1-mediated gene activation across the tested cell lines (Supplementary Figure 6D-F). The functional association with both EWS/FLI and LSD1 function was likewise observed for common EWS/FLI-LSD1 co-peaks (Supplementary Figure 6G-H). These

116 findings further support a role for LSD1 in EWS/FLI-mediated transcriptional activation in Ewing sarcoma. 
117 We next asked whether EWS/FLI-LSD1 colocalized peaks were also associated with an EWS/FLI-

118 mediated gain of activating histone marks. We examined the levels of H3K27ac, H3K4me1, H3K4me2,

119 and H3K4me3 at loci with EWS/FLI and LSD1 colocalization in A673 cells (wildtype levels of EWS/FLI

120 expression) or cells with EWS/FLI knockdown (EFKD cells). EWS/FLI-LSD1 colocalization was highly

121 associated with increased H3K27ac, consistent with the establishment of a chromatin state which

122 enhances gene activation (Figure $1 \mathrm{H}-\mathrm{I}$ ). Modest increases of uncertain significance were observed for

$123 \mathrm{H} 3 \mathrm{~K} 4$ mono- and dimethylation, suggesting that LSD1 may not demethylate H3K4 as its primary activity

124 at EWS/FLI-bound loci (Supplementary Figure 7A-B).

\section{LSD1 is enriched at both GGAA-microsatellites and non-microsatellites}

126 EWS/FLI-mediated gene activation is often modeled as a function of de novo enhancer formation

127 following EWS/FLI binding at GGAA- $\mu$ sats, both proximal and distal to target genes. ${ }^{5,8,38}$ This process

128 involves recruitment of co-activators such as $\mathrm{p}^{300^{8}}$ and $\mathrm{BAF}^{5}$ by the EWS domain. Given that LSD1-

129 bound regions more strongly associated with gene activation and that inhibition of LSD1 downregulates

130 EWS/FLI-activated genes, we hypothesized that LSD1 would localize to at GGAA- $\mu$ sats as part of the co-

131 activating machinery assembled by EWS/FLI. We split EWS/FLI-bound loci into GGAA- $\mu$ sats and non-

132 microsatellites ("non- $\mu$ sats") and evaluated EWS/FLI and LSD1 binding at both (Figure 2A,

133 Supplementary Figure 8A-C). While the EWS/FLI binding was stronger at GGAA- $\mu$ sats than non- $\mu$ sats,

134 we were surprised that LSD1 was enriched at both GGAA- $\mu$ sats and non- $\mu$ sats. The heights of the peaks

135 in the profile plots in Figure 2A and Supplementary Figure 8A-C suggest the amounts of LSD1

136 colocalized relative to EWS/FLI may be higher at non- $\mu$ sat loci and LSD1 binding overlapped a majority of

137 EWS/FLI-bound non- $\mu$ sat regions in all cell lines. The results of HOMER motif analysis for LSD1 further

138 reflected a bias toward localization of LSD1 at non- $\mu$ sats, as the consensus ETS motif consistently

139 ranked as the most enriched sequence under LSD1 peaks, albeit with GGAA- $\mu$ sats as the second highest

140 (Figure 2B, Supplementary Figure 8D). These data suggest LSD1 recruitment occurs in a manner distinct

141 from BAF and p300 recruitment as these factors are primarily associated with GGAA- $\mu$ sat-bound

142 EWS/FLI.

Non-microsatellites play a role in Ewing sarcoma super-enhancers

144 That LSD1 functions to promote gene activation from both non- $\mu$ sat and GGAA- $\mu$ sat loci across the

145 genome is consistent with the previous observation that LSD1 inhibition reverses significant portions of

146 EWS/FLI-mediated transcriptional activity. ${ }^{17}$ We were, however, intrigued by the observations that

147 EWS/FLI-LSD1 sites tended to associate more strongly with non- $\mu$ sats, as GGAA- $\mu$ sats are among the

148 most EWS/FLI-responsive elements in Ewing sarcoma. It was unclear how this mechanism fit the model

149 wherein gene activation in Ewing sarcoma is primarily driven by EWS/FLI-mediated changes to the

150 enhancer landscape, through de novo deposition of H3K27ac and recruitment of chromatin remodelers to

151 GGAA- $\mu$ sats. 
To further understand the role of LSD1 in EWS/FLI-mediated gene activation, we analyzed the genomewide relationship between EWS/FLI, LSD1, and the enhancer landscape in A673 cells in more detail. First, we assessed the relationship between super-enhancers (SEs) and EWS/FLI. Using H3K27ac signal overlapping with H3K4me1 signal to define enhancer regions, the Ranked Ordering of Super-Enhancers (ROSE) algorithm ${ }^{39,40}$ identified 833 SEs in A673 cells (Figure 3A, Supplementary Figure 9A; Supplementary Tables 1-2). Previous reports suggest de novo enhancers at GGAA- $\mu$ sats constitute the majority of SEs in A673 cells ${ }^{41}$; we were thus surprised our analysis showed only $20 \%$ of SEs overlapped

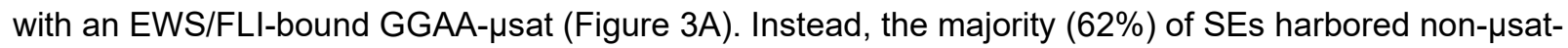
bound EWS/FLI including 45\% that had no GGAA- $\mu$ sat-bound EWS/FLI and $17 \%$ that had both non- $\mu$ satand GGAA- $\mu$ sat-bound EWS/FLI (Figure 3A). Genes nearest to SEs showed higher levels of expression compared to those near typical enhancers (TEs) ( $p<0.001$; Figure 3B), as expected. Taken together,

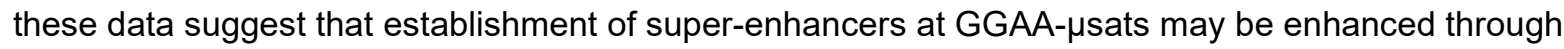
additional EWS/FLI binding at non- $\mu$ sat sites.

De novo establishment of enhancers at GGAA- $\mu$ sats is unique to Ewing sarcoma, due to the altered binding specificity conferred to the FLI DBD in the fusion. ${ }^{12,42}$ Because of the observation that SEs in Ewing sarcoma cells contained both GGAA- $\mu$ sats and non- $\mu$ sats, we next investigated how the type of EWS/FLI binding site (or sites) contained within a SE determined the stability of that SE in the absence of EWS/FLI. Following EWS/FLI-depletion (Supplementary Figure 9B-C), 315 (38\%) of all SEs collapsed and 700 new SEs were established in EFKD cells (Figure 3C, Supplementary Figure 9D; Supplementary Tables 3-4). Of the 315 SEs which collapsed 234 (74\%) were reconstituted in cells rescued with ectopic EWS/FLI expression (wtEF cells) (Figure 3C). Rescue also resulted in 493 (70\%) of the 700 EFKDspecific SEs collapsing (Figure 3C, Supplementary Figure 9E; Supplementary Tables 5-6). SEs which contained any GGAA- $\mu$ sat were less stable in EFKD cells (46\% persist) than SEs either overlapping only a non- $\mu$ sat EWS/FLI site or containing no EWS/FLI binding (non- $\mu$ sat only: 67\% persist, no EWS/FLI: $64 \%$ persist, Figure 3D). This was true for both GGAA- $\mu$ sat-containing SEs which overlapped a non- $\mu$ sat ("both"; 49\% persist, Figure 3D) and those that did not (" $\mu$ sat"; 30\% persist, Figure 3D). These data suggest GGAA- $\mu$ sat-associated SEs are more dependent on EWS/FLI-binding and are more likely to collapse when EWS/FLI is depleted compared to non- $\mu$ sat-associated SEs.

Consistent with these data, genes nearest to SEs containing an EWS/FLI-bound GGAA- $\mu$ sat were upregulated by EWS/FLI as compared to those near SEs lacking a GGAA- $\mu$ sat, which were slightly downregulated (Figure 3E). These data suggest that the transcriptional machinery may preferentially accumulate at SE loci bound by EWS/FLI at GGAA- $\mu$ sats, effectively sequestering these complexes away from other SEs and leading to a reduction of transcription levels where SEs do not contain a GGAA- $\mu$ sat.

\section{LSD1 enhances the establishment of super-enhancers by EWS/FLI}


Having observed that many Ewing sarcoma SEs also contain non- $\mu$ sat sites, we next asked whether LSD1 was also present in these SEs, and whether the LSD1 harbored in SEs might be colocalized with, or bind independently from, EWS/FLI. In other non-Ewing sarcoma contexts, LSD1 is enriched at SEs ${ }^{43}$, though its function is unclear. LSD1 is also implicated in genome-wide maintenance of primed enhancers. ${ }^{44}$ We found $95 \%$ of A673 SEs overlapped an LSD1 peak. There were $64 \%$ of SEs overlapping a locus with colocalized EWS/FLI and LSD1, while 31\% of SEs were overlapping an LSD1 peak without any colocalized EWS/FLI (Figure 3F, Supplementary Table 2).

To determine the functional relationship between LSD1, EWS/FLI, and SEs in A673 cells, we analyzed SEs based on their EWS/FLI and LSD1 binding status. SEs possessing an EWS/FLI-LSD1 coincident peak had significantly higher H3K27ac scores than SEs containing either non-overlapping EWS/FLI and/or LSD1 peaks ( $p<0.01$ ), or neither EWS/FLI nor LSD1 ( $<<0.01$; Figure $3 G)$. While there was no significant difference in base expression of the nearest gene (Supplementary Figure 9F), those SEs which lacked EWS/FLI-LSD1 co-peaks showed decreased gene expression in the presence of EWS/FLI (Figure $3 \mathrm{H}$ ). That the highest levels of H3K27ac were seen at SEs where EWS/FLI and LSD1 are colocalized, and that genes near SEs which lack this colocalization tend to be downregulated by EWS/FLI, suggests that the cooperation between EWS/FLI and LSD1 promotes deposition of H3K27ac and may lead to preferential accumulation of transcriptional machinery.

Having focused primarily on SEs in A673s cells, we next asked whether these relationships between EWS/FLI, LSD1, and histone H3K27ac deposition was a common feature across Ewing sarcoma cell lines. We found that a majority of SEs overlapped non- $\mu$ sat-bound EWS/FLI, either with or without overlap of a GGAA- $\mu$ sat in A673, EWS-502, and SK-N-MC cells (Supplementary Figure 10A-C). TC71 cells had fewer SEs overlapping EWS/FLI, but most of those TC71 SEs with EWS/FLI binding were also overlapping a non- $\mu$ sat. (Supplementary Figure 10D). A significant portion of SEs overlapping EWS/FLI also overlapped with LSD1 binding (Supplementary Figure 10E-H) and H3K27ac deposition was highest at those SEs with EWS/FLI-LSD1 colocalization (Supplementary Figure 10I-L) across all cell lines.

Other studies have suggested LSD1 acts genome-wide to maintain active and primed enhancers, and it is proposed that LSD1 does this by functioning as a repressor and preventing over-activation. ${ }^{44}$ In order to clarify whether LSD1 at EWS/FLI-activated enhancers was simply part of this repressive maintenance function, or instead whether LSD1 promoted enhancer activity, we used GSEA to ask how LSD1 regulated genes near SEs with colocalized EWS/FLI and LSD1. We found that these genes were functionally associated with LSD1-mediated gene activation across all cell lines (Supplementary Figure $11 \mathrm{~A}-\mathrm{D})$, suggesting that LSD1 is not functioning as a repressor at the enhancers associated with these genes. Together, these results show LSD1 colocalized at EWS/FLI-bound non- $\mu$ sat loci correlates with increased H3K27ac deposition. This occurs regardless of whether the SE also overlaps an EWS/FLIbound GGAA- $\mu$ sat. A model for this will be more fully described in the Discussion section below. 


\section{EWS/FLI causes dynamic reorganization of LSD1 genome-wide}

222 Functional association of EWS/FLI with LSD1 could occur through 1) active redistribution of LSD1 caused

223 by EWS/FLI or 2) binding of EWS/FLI at loci preloaded by LSD1 in a precursor cell. To determine which

224 of these mechanisms operates in Ewing sarcoma, we evaluated LSD1 occupancy in either parental A673

225 cells or EFKD cells. We additionally included EFKD cells rescued with ectopic expression of EWS/FLI,

226 wtEF cells. Panels show specific examples at LMO2 and SERPINE1 where EWS/FLI depletion drives

227 reversible changes in LSD1 binding in Figure 4A-B and Supplementary Figure 12. Globally, LSD1 was

228 bound at 40262 loci in A673 cells, 33085 loci in EFKD cells, and 39659 loci in wtEF cells (Figure 4C). We

229 observed 16698 LSD1 peaks present in A673 cells that collapse in EFKD cells, 9197 of which are rescued in wtEF cells (Figure 4C). Of the 10151 loci which gain LSD1 peaks following EWS/FLI depletion, 7459 loci lose LSD1 binding upon rescue with ectopic EWS/FLI expression. Notably, while we initially observed 21950 LSD1-bound loci were "stable" across the tested conditions, a closer inspection revealed more dynamism within these stable peaks than we had appreciated. Of these "stable" peaks, 5687 show increased LSD1 binding in A673 as compared to EFKD, and 9271 show greater binding in EFKD cells as compared to A673, further supporting that EWS/FLI expression results in genome-wide reorganization of LSD1 (Figure 4D).

237 Considering the widespread redistribution of LSD1, we next asked whether LSD1 colocalizes with

$238 \mathrm{EWS} / \mathrm{FLI}$ at new sites in the genome, or if EWS/FLI instead binds at loci which already possess LSD1.

239 Venn diagram analysis showed most LSD1 peaks present in A673 cells were also present in EFKD cells

240 (Figure 4C). Of the EWS/FLI-LSD1 colocalized peaks, 54\% show increased LSD1 binding in A673 cells,

241 with LSD1 binding at a new locus with EWS/FLI 30\% of the time, while another $24 \%$ show increased

242 LSD1 binding with EWS/FLI expression (Figure 4E). These data suggest both that LSD1 is recruited to

243 new sites and that EWS/FLI binds at sites already bound by LSD1. At these latter sites, we speculate that

244 LSD1 may interact with other ETS factors when EWS/FLI is absent and that EWS/FLI may displace these

245 ETS factors, as has been previously suggested, ${ }^{8}$ and hijack LSD1 activity.

\section{LSD1 binds at activating "super-clusters"}

247 We were struck by the visual clustering of LSD1 peaks in cells with depleted EWS/FLI expression, as 248 shown in Figure 4A and 4B. Because clustering of chromatin regulatory proteins, including LSD1, is 249 reported at SEs, we investigated the relationship between LSD1 "super-clusters" (SCs) and SEs in EFKD 250 cells. The ROSE algorithm identified 970, 1287, and 1325 LSD1 SCs in A673, EFKD, and wtEF cells,

251 respectively (Figure 5A, Supplementary Tables 15-20). These are regions with the highest levels of LSD1

252 binding throughout the genome, as defined by a function of rank and LSD1 signal (Figure 5B-C,

253 Supplementary Figure 13A). Reflecting global LSD1 binding, we observed EWS/FLI-driven dynamism in

254 the genome-wide distribution of LSD1 SCs. There were 426 LSD1 SC's present in A673 cells that

255 collapse in EFKD cells, 269 of which are rescued in wtEF cells (Figure 5A). Of the 753 loci which gain 
LSD1 clusters following EWS/FLI depletion, 498 loci lose LSD1 binding upon rescue. LSD1 clusters are stable regardless of EWS/FLI status at 486 loci.

Due to notable overlaps between LSD1 SCs and SEs at individual loci, such as those shown at CCND1 (Figure 5D), DUSP6 (Supplementary Figure 13B), ETS1 (Supplementary Figure 13C), and TGFBI (Supplementary Figure 13D), we initially considered whether LSD1 SCs simply represented SEs. However, only 320 A673 SCs (33\%) and 482 EFKD SCs (37\%), and 510 wtEF SCs (38\%) overlapped with SEs in their respective cells (Figure 5E-G), instead suggesting a heretofore unappreciated chromatin-associated LSD1-organizational structure. GSEA revealed that LSD1 SCs were associated with both LSD1-mediated gene activation (NES=1.990, $p<0.001$; Figure $5 \mathrm{H}$ ) and EWS/FLI-mediated gene activation (NES=2.358, $p<0.001$; Figure $5 \mathrm{I}$ ) in A673 cells, consistent with prior observations that LSD1 plays a role in EWS/FLI-mediated activation. In contrast, in EFKD cells, LSD1 SCs were strongly associated with genes that are repressed by EWS/FLI and thus become activated in the knockdown condition (NES=-2.526, $p<0.001$; Figure $5 \mathrm{~J}$ ), again supporting a role for LSD1 in gene activation, even in the absence of EWS/FLI. Most of the genes in the leading edge of this latter GSEA have SCs that collapse with wildtype levels of EWS/FLI (Figure 5K). We speculate that LSD1 SCs are associated with gene activation in a Ewing sarcoma precursor cell, and that during the process of Ewing sarcoma development these activating LSD1 SCs collapse and expression of nearby genes is downregulated. In Ewing sarcoma cells new LSD1 SCs are formed.

Although the overlap of LSD1 SCs with SEs in EFKD cells was partial, we found an overwhelming majority (95.6\%) of SEs in these cells overlapped at least one LSD1 peak (Figure 5L, Supplementary table 19). This was similar to our prior observations of SEs in A673 cells (Figure 3F). 39.9\% of superenhancers overlapped an LSD1 SC, while $55.7 \%$ overlapped a "monopeak" (LSD1 bound in an individual peak, not as part of a cluster). A similar distribution was seen for SEs in A673 and wtEF cells (Supplementary Figure 14A-B). In all conditions, those SEs overlapping an LSD1 SC had greater H3K27ac scores than those with only a monopeak, or no LSD1 (Figure 5M, Supplementary Figure 14CD), suggesting a functional role for the factors that recruit LSD1 in promoting the establishment of enhancers. No significant difference was observed in basal expression of SE-associated genes based on LSD1 binding status (Supplementary Figure 14E-G), but genes near EFKD SEs containing an LSD1 SC showed greater downregulation with EWS/FLI expression than genes near SEs without an LSD1 SC (Figure 5N). In cells expressing EWS/FLI, EWS/FLI-mediated regulation of SE-associated genes showed no such dependency on LSD1 configuration within the SE (Supplementary Figure 14H-I). Interestingly, of the 251 SEs that both 1) are unique to EFKD and 2) overlap an LSD1 SC, 196 (78\%) have SCs that are also unique to EFKD cells (Supplementary Figure 14J), indicating a concurrent collapse of both the LSD1 SC and the SE upon EWS/FLI expression. Taken together, these data support a second novel model for EWS/FLI-mediated repression via aberrant enhancer regulation: EWS/FLI-induced LSD1 SC collapse prevents priming and maintenance of enhancers active in the Ewing sarcoma precursor cell. Moreover, 
bioRxiv preprint doi: https://doi.org/10.1101/2020.05.05.079533; this version posted May 7, 2020. The copyright holder for this preprint (which was not certified by peer review) is the author/funder, who has granted bioRxiv a license to display the preprint in perpetuity. It is made available under aCC-BY-NC-ND 4.0 International license.

292 once EWS/FLI is introduced to the cell, the primacy of EWS/FLI-mediated transcriptional regulation 293 overtakes that of LSD1-SCs in the determination of gene expression. 


\section{DISCUSSION}

296 The close phenotypic overlap between LSD1 inhibition (with SP2509) and EWS/FLI depletion in A673 (or

297 EWS/ERG depletion in TTC-466 cells) suggested that LSD1 is closely linked to the genome-wide activity

298 of oncogenic fusions in Ewing sarcoma. ${ }^{17}$ Prior studies suggested that LSD1 is part of a NuRD-LSD1

299 complex hijacked by EWS/FLI to repress tumor suppressors, but how LSD1 was involved in EWS/FLI-

300 mediated gene activation was unclear. ${ }^{9}$ To understand this relationship, we used genomic approaches to

301 probe LSD1 distribution and function in four Ewing sarcoma cell lines, and a model of the Ewing sarcoma

302 precursor cell with diminished EWS/FLI expression, EFKD, complemented with rescue using ectopic

303 EWS/FLI expression, wtEF. Though EFKD cells are an imperfect precursor model, we believe they are

304 both conceptually and technically useful in that they are a system which tolerates EWS/FLI (re-

305 )introduction. Importantly, following EWS/FLI depletion, they continue to proliferate ${ }^{10}$, enabling the

306 requisite large numbers of cells needed for chromatin-level analyses.

307 We found that LSD1 is broadly important for gene activation, functioning at enhancers in both Ewing 308 sarcoma and precursor cells, and that EWS/FLI drives dynamic genome-wide reorganization of LSD1.

309 Functional interaction between EWS/FLI and LSD1, particularly at non- $\mu$ sat sites, is critical to restructure the enhancer landscape in Ewing sarcoma cells as modeled in Figure 6. Here, we build on previous studies that show de novo enhancer formation at EWS/FLI-bound GGAA- $\mu$ sats and found that these

312 enhancers almost always also involve an EWS/FLI-bound HA site (Figure 6A Panel i). LSD1 is frequently 313 recruited to these collaborating loci and the presence of LSD1 augments enhancer formation, resulting in

314 increased H3K27ac deposition. Panel ii depicts enhancers which are solely driven by HA sites. In

315 precursor cells, these are likely bound by other ETS transcription factors and LSD1. In Ewing sarcoma

316 cells, it is probable that EWS/FLI hijacks these sites through displacement of the endogenous ETS factor

317 while retaining LSD1 binding.

318 The dynamic reorganization of LSD1 SCs is shown in Panel iii. In precursor cells, LSD1 SCs promote 319 nearby enhancer formation and gene activation. Expression of EWS/FLI disrupts these loci, causing collapse of LSD1 SCs and the associated super-enhancers, leading to downregulation of nearby genes. EWS/FLI thus engages distinct mechanisms to alter the function of LSD1-containing complexes: 1)

322 through direct recruitment of the NuRD-LSD1 complex previously described ${ }^{9}$ and 2) through

323 reorganization of LSD1 and LSD1 SCs.

324 This model is compelling because it enhances our understanding of aberrant epigenomic regulation 325 driven by EWS/FLI. Our results suggest that EWS/FLI-bound GGAA- $\mu$ sats may depend upon another 326 EWS/FLI binding event at a non- $\mu$ sat to target the enhancer activity. Recruitment of LSD1 to these non$327 \mu$ sat sites further augments EWS/FLI-mediated enhancer formation, and this occurs even in the absence of GGAA- $\mu$ sats. These findings unite important observations regarding the involvement of both GGAA-

$329 \mu$ sats and LSD1 in EWS/FLI-mediated gene activation. We further identified two novel mechanisms for 
gene downregulation by EWS/FLI, and both are intricately linked to altered enhancer function. First, there exist some SEs which show decreased transcriptional activity with EWS/FLI expression. These SEs frequently do not overlap either colocalized EWS/FLI-LSD1 or a GGAA- $\mu$ sat, suggesting that transcriptional machinery preferentially accumulates at SEs where EWS/FLI both binds a GGAA- $\mu$ sat and is colocalized with LSD1, while transcriptional machinery is depleted at other SEs lacking EWS/FLI binding. Second, EWS/FLI-induced collapse of LSD1 SCs leads to decreased enhancer priming. Despite the strong transcriptional activation capacity of the EWS domain, expression of EWS/FLI results in a greater number of genes repressed than activated, and these two mechanisms likely contribute to this process.

LSD1 is important for enhancer decommissioning during differentiation ${ }^{23}$ and LSD1 constructs fused to transcription activator-like effector (TALE-LSD1) or enzymatically dead Cas9 (dCas9-LSD1) show that LSD1 silences enhancers and promoters when targeted to specific genomic loci. ${ }^{45,46}$ More recent studies highlight a role for LSD1 involvement in enhancer silencing by lineage-specific transcription factors like

343 GFI1 in acute myeloid leukemia ${ }^{25}$ and medulloblastoma ${ }^{47}$, or BCL6 in diffuse large B-cell lymphoma. ${ }^{24}$ In

344 these cases, inhibition of LSD1 with derivatives of tranylcypromine restores enhancer function and

345 disrupts oncogenic gene regulation. However, we observed LSD1 to be largely associated with gene activation in Ewing sarcoma. Indeed, knockdown of LSD1 results in the downregulation of activated genes nearby ${ }^{34}$ indicating that LSD1 is not functioning to suppress over-activation, but is instead critically important to maintain gene activation. How EWS/FLI enforces an activating role for LSD1 is unknown, but the activity observed is similar to LSD1 activity in prostate cancer. In prostate cancer LSD1 activates oncogenic gene transcription independently from its enzymatic function. ${ }^{48,49}$ Interestingly, both Ewing sarcoma and prostate cancer show sensitivity to reversible LSD1 inhibition with SP2509, but not other classes of irreversible LSD1 inhibitors related to tranylcypromine. ${ }^{34,49}$ This suggests that different functions of LSD1 may be differentially targeted by different classes of LSD1 inhibitors. The specific mechanistic role LSD1 is playing here, whether non-enzymatic or through demethylation of targets other than $\mathrm{H} 3 \mathrm{~K} 4$, is not yet known and remains an important area of future study.

In conclusion, EWS/FLI interacts with LSD1 to mediate genome-wide epigenetic and transcriptional changes in Ewing sarcoma. EWS/FLI induces a dynamic reorganization of LSD1 that acts in concert with EWS/FLI activity at GGAA- $\mu$ sats to reshape the enhancer landscape. The involvement of widespread localization of LSD1 at EWS/FLI-bound non- $\mu$ sats suggests that EWS/FLI-mediated chromatin regulation in Ewing sarcoma requires widespread activity at loci beyond GGAA- $\mu$ sats. The mechanisms which drive this non- $\mu$ sat-mediated regulation are poorly understood and represent critical facets of EWS/FLI function to explore. We also show that LSD1 binds chromatin in a "clustered" configuration. While a similar binding pattern has been observed for LSD1 enriched at SEs, we found an imperfect overlap between LSD1 clusters and SEs. This study suggests that understanding how these clusters form and function, and how 
bioRxiv preprint doi: https://doi.org/10.1101/2020.05.05.079533; this version posted May 7, 2020. The copyright holder for this preprint (which was not certified by peer review) is the author/funder, who has granted bioRxiv a license to display the preprint in perpetuity. It is made available under aCC-BY-NC-ND 4.0 International license.

365 perturbations occur in disease, could provide clues on how to better target LSD1 function in Ewing 366 sarcoma patients, as well as in other malignancies. 
MATERIALS AND METHODS

\section{Key Resources}

Key resources required for this protocol are listed in Supplementary Table 21.

\section{Cell Lines}

372 All cell lines included are tested for mycoplasma annually and sent for STR profiling every two years.

373 All cell lines recently tested negative for mycoplasma and were most recently authenticated by STR

374 profiling in 2018. We should note that we have used the SK-N-MC and A673 lines. These were

375 previously misidentified as neuroblastoma and rhabdomyosarcoma lines, respectively, but actually

376 contain the EWS/FLI fusion and are Ewing sarcoma cell lines.

377 All Ewing sarcoma cells were cultured at $37^{\circ} \mathrm{C}, 5 \% \mathrm{CO}_{2}$. A673 and SK-N-MC cells were cultured in 378 DMEM (Corning Cellgro 10-013-CV) containing 10\% fetal bovine serum (FBS, Gibco 16000-044), 379 penicillin/streptomycin/glutamine (PSQ, Gibco 10378-016), and sodium pyruvate (Gibco 11360-070). 380 EWS-502 and TC71 cells were cultured in RPMI (Corning Cellgro 15-040-CV) containing 10\% FBS for 381 TC71 cells and 15\% FBS for EWS-502 cells, as well as P/S/Q. A673 cells are derived from the tumor of a 382 14-year old Japanese female, contain a type I EWS/FLI fusion, have mutant TP53 (Q119fs) and wildtype 383 STAG2. EWS-502 cells are derived from a Ewing sarcoma patient of unspecified sex and age, and have mutant TP53 (C135F) and STAG2 loss. SK-N-MC cells are derived from the tumor of a 12-year old female, have truncated TP53, and wildtype STAG2. TC71 cells are derived from the tumor of a 22-year old male, have mutated TP53 (R213*), and have wildtype STAG2.

HEK293-EBNA cells were grown at $37^{\circ} \mathrm{C}, 5 \% \mathrm{CO}_{2}$ in DMEM supplemented with $10 \% \mathrm{FBS}$, penicillin/streptomycin/glutamine, and $0.3 \mathrm{mg} / \mathrm{mL}$ geneticin (Gibco 10131-027). These cells are derived from the kidney of a healthy aborted fetus, presumed female. Cells were originally transformed by culturing with sheared adenovirus 5 .

\section{Retrovirus Production}

392 To generate retroviruses of the previously reported constructs for iLuc and iEF-2 shRNAs, as well as cDNA for 3XFLAG- 222 and 3XFLAG-EWS/FLI ${ }^{10}$, HEK293-EBNA cells were co-transfected with retroviral expression plasmids, vesicular stomatitis virus G glycoprotein (VSV-G) and gag/pol packaging plasmids using Mirus Bio TransIT-LT1. Following 48 hours virus-containing supernatant was collected and filtered.

396 Retrovirally infected $A 673$ cells were selected in $2 \mu \mathrm{g} / \mathrm{mL}$ puromycin (Sigma P8833) for a minimum of 72 397 hours. For rescued cells, infection occurred after 72 hours of puro selection and cells were double 398 selected for 7 additional days in puro with $100 \mu \mathrm{g} / \mathrm{mL}$ hygromycin B. 
For validation of protein knockdown, samples were run on 4-15\% Mini-PROTEAN TGX precast gels (BioRad) using $90 \mathrm{~V}$ for 15 minutes and $120 \mathrm{~V}$ for 50 minutes. Proteins were blotted to nitrocellulose membranes using semi-dry transfer with the Bjerrum Schaffer-Nielsen buffer at $15 \mathrm{~V}$ for 60 minutes. Membranes were blocked at $4^{\circ} \mathrm{C}$ overnight in Odyssey Blocking Buffer PBS (LI-COR), and incubated with primary antibody overnight at $4^{\circ} \mathrm{C}$. Primary antibodies used for immunoblotting were: anti-FLI (Abcam ab15289), anti-H3 (Cell Signaling Technology \#4499 - D1H2), anti-Lamin B1 (Abcam ab16048), and antiFLAG M2 (Sigma F3165). For validation of protein depletion with knockdown, FLI, total H3, Lamin, and FLAG blots were incubated with IRDye secondary antibodies (LI-COR) and developed on the Odyssey.

\section{Chromatin Immunoprecipitation and Sequencing (ChIP-seq)}

For performing chromatin immunoprecipitation, A673 cells were seeded in 15-cm dishes. Cells were removed by scraping in plain media and pelleted at $1200 \mathrm{rpm}$ for $5 \mathrm{~min}$. Pellets were resuspended in room temperature cell lysis buffer (20 mM HEPES-KOH, pH 8.0; 1 mM EDTA; 0.5 mM EGTA; 140 mM $\mathrm{NaCl} ; 10 \%$ glycerol; $0.5 \%$ NP-40; $0.25 \%$ Triton X-100; protease inhibitor) and incubated on ice for 5 min before nuclei were pelleted at $1200 \mathrm{rpm}$ for $5 \mathrm{~min}$. Nuclei were washed once in $1 \mathrm{~mL}$ MNase digestion buffer (20 mM Tris-Cl. pH 7.4; $5 \mathrm{mM} \mathrm{MgCl}_{2} ; 1 \mathrm{mM} \mathrm{CaCl}_{2} ; 0.1 \%$ Triton X-100, protease inhibitor) and resuspended in MNase digestion buffer. $50 \mathrm{U}(10 \mu \mathrm{L}$ of $5 \mathrm{U} / \mu \mathrm{L})$ MNase were added and nuclei were incubated at $37^{\circ} \mathrm{C}$ for 30 minutes with gentle inversion every 10 minutes. Digestion was stopped by the addition of chilled $100 \mu \mathrm{L}$ 0.5M EDTA followed by a 5-minute incubation on ice. Nuclei were cleared with a spin at $13000 \mathrm{rpm}$ for 10 minutes and the resulting supernatant (chromatin) was transferred to a new tube. Chromatin concentration was quantified by Nanodrop and $100 \mu \mathrm{g}$ of chromatin was used for each immunoprecipitation, diluted to equal volumes in dilution buffer $(20 \mathrm{mM}$ Tris-Cl, pH 7.4; 2 mM EDTA; 50 $\mathrm{mM} \mathrm{NaCl} ; 0.25 \%$ Triton X-100; $20 \mathrm{mg} / \mathrm{mL}$ BSA; protease inhibitor) with $50 \mu \mathrm{L}$ of $0.5 \mathrm{M}$ EDTA. Chromatin was added to antibody coated magnetic Dynabeads for $16-20$ hours at $4^{\circ} \mathrm{C}$. Antibodies used for ChIP were: anti-H3K4me1 (ab8895), anti-H3K4me2 (ab32356), and anti-H3K4me3 (ab8580). Beads were washed with ChIP wash buffers containing $0.1 \%$ SDS and $150 \mathrm{mM} \mathrm{NaCl}, 150 \mathrm{mM} \mathrm{NaCl}$, and $250 \mathrm{mM}$ LiCl. ChIP DNA was eluted with fresh elution buffer, RNAse and Proteinase $\mathrm{K}$ treated and decrosslinked overnight at $65^{\circ} \mathrm{C}$. DNA was then purified with phenol-chloroform using the Qiagen MaXtract extraction kit as per manufacturer's instructions. DNA was quantified by Qubit and validated for enrichment by qPCR using specific primers. Following validation, libraries were generated for sequencing using the NEBnext kit according to manufacturer's instructions and submitted for deep sequencing on the Illumina HiSeq 4000 platform (Nationwide Children's Hospital Institute for Genomic Medicine). Native histone ChIPs were performed three times, with a non-specific IgG negative control.

\section{Cleaveage Under Targets and Release Using Nuclease (CUT\&RUN) and Cleavage Under Targets} and Tagmentation (CUT\&Tag)

Cell Preparation 
CUT\&RUN and CUT\&Tag were performed as described ${ }^{53,54}$ with slight modifications. BioMag® Plus Concanavalin A-coated magnetic beads (Bangs Laboratories, BP531; $10 \mu$ l beads per condition) were washed twice with Binding buffer (20 mM HEPES-KOH pH 7.9, $10 \mathrm{mM} \mathrm{KCl}, 1 \mathrm{mM} \mathrm{CaCl}, 1 \mathrm{mM} \mathrm{MnCl}$ ) in preparation for CUT\&RUN/CUT\&Tag. 500,000 cells (CUT\&RUN) and 250,000 cells (CUT\&Tag) per condition were washed twice with Wash Buffer (20 mM HEPES-NaOH pH 7.5, $150 \mathrm{mM} \mathrm{NaCl}, 0.5 \mathrm{mM}$ Spermidine, Protease Inhibitor) and rotated with prepared beads for 10 minutes at room temperature. The supernatant was cleared and removed using a magnet stand. The beads were resuspended in $100 \mu \mathrm{L}$ Antibody Buffer (20 mM HEPES-NaOH pH 7.5, $150 \mathrm{mM} \mathrm{NaCl}, 0.5 \mathrm{mM}$ Spermidine, 0.02\% Digitonin [CUT\&RUN] or $0.05 \%$ digitonin [CUT\&Tag], 2 mM EDTA, Protease Inhibitor) and antibodies (FLI 7.3 mouse, Santa Cruz; H3K27ac rabbit, Abcam ab4729; Rabbit anti-mouse IgG, Abcam ab46540; LSD1 rabbit, Abcam ab17721) were added at a dilution of 1:100. Samples were rotated overnight at $4^{\circ} \mathrm{C}$. The samples were cleared on a magnet stand and beads were washed with Dig-wash buffer (20 mM HEPES$\mathrm{NaOH}$ pH 7.5, $150 \mathrm{mM} \mathrm{NaCl}, 0.5 \mathrm{mM}$ Spermidine, 0.02\% Digitonin [CUT\&RUN] or 0.05\% digitonin [CUT\&Tag]).

CUT\&RUN (FLI, LSD1, H3K27ac, and Rb IgG)

Beads that were incubated with FLI 7.3 mouse antibody were resuspended in $100 \mu \mathrm{L}$ Dig-wash buffer and incubated with rabbit anti-mouse secondary antibody (Abcam, ab46540) at a dilution of 1:100 on a rotator for 1 hour at $4^{\circ} \mathrm{C}$. All other samples didn't require a secondary antibody step. After another wash with Digwash buffer, beads were resuspended in $100 \mu \mathrm{L}$ Dig-wash buffer and Protein A-MNase fusion protein (generously provided by the Henikoff lab) was added to a final concentration of $700 \mathrm{ng} / \mathrm{mL}$. Samples were rotated for 1 hour at $4^{\circ} \mathrm{C}$. After 2 washes with Dig-wash buffer, beads were resuspended in $100 \mu \mathrm{L}$ Digwash buffer and placed in ice water to equilibrate to $0^{\circ} \mathrm{C} . \mathrm{CaCl}_{2}$ was added to a final concentration of 2 $\mathrm{mM}$ under gentle vortexing and samples were incubated for 45 minutes (H3K27ac) or 2 hours (FLI, LSD1) at $0^{\circ} \mathrm{C}$. Reactions were stopped by adding $100 \mu \mathrm{l}$ XSTOP buffer ( $340 \mathrm{mM} \mathrm{NaCl}, 20 \mathrm{mM}$ EDTA, $4 \mathrm{mM}$ EGTA, $0.02 \%$ Digitonin, $0.05 \mathrm{mg} / \mathrm{mL}$ RNase A, $0.05 \mathrm{mg} / \mathrm{mL}$ Glycogen containing $2 \mathrm{pg} / \mathrm{mL}$ heterologous Yeast Spike-in DNA) and incubated at $37^{\circ} \mathrm{C}$ for 10 minutes to release the CUT\&RUN fragments. Beads were pelleted by centrifugation at $16,000 \times \mathrm{g}$ and $4^{\circ} \mathrm{C}$ for 5 minutes and supernatants containing CUT\&RUN fragments were transferred to new tubes. SDS was added to a final concentration of $0.1 \%$ and Proteinase $\mathrm{K}$ to a final concentration of $0.25 \mu \mathrm{g} / \mu \mathrm{L}$ followed by an incubation at $70^{\circ} \mathrm{C}$ for 10 minutes. DNA from all supernatants was purified using Phenol/Chloroform extraction and ethanol precipitation.

The library prep was performed using the KAPA Hyper Prep Kit (KAPA Biosystems, KK8502) in combination with the KAPA Dual-Indexed Adapter Kit (KAPA Biosystems, \#KK8722) with several modifications. $50 \mu \mathrm{L}$ of CUT\&RUN sample were used for the End repair and A-tailing step. A $1.5 \mu \mathrm{M}$ adapter stock was used for the adapter ligation reaction with a 20 -minute incubation step at $20^{\circ} \mathrm{C}$. After the recommended post-ligation cleanup, the DNA was eluted in $53 \mu \mathrm{L}$ elution buffer and a second cleanup was performed using $50 \mu \mathrm{L}$ of eluted DNA and $65 \mu \mathrm{L}$ Agencourt AMPure XP magnetic beads 
471 (Beckman Coulter, A63880). The DNA was eluted with $25 \mu \mathrm{L}$ elution buffer and $20 \mu \mathrm{L}$ were used for the

472 library amplification. To favor small fragments, the amplification was performed using a combined

473 Annealing/Extension step at $60^{\circ} \mathrm{C}$ for 10 seconds and 13 cycles. $50 \mu \mathrm{L}$ of the amplified library and 57.5

$474 \mu \mathrm{L}$ AMPure beads (1.15X) were used for the first post-amplification cleanup. After eluting the DNA with

$47553 \mu \mathrm{L}$, a second post-amplification cleanup step was performed using $50 \mu \mathrm{L}$ eluted DNA and $62.5 \mu \mathrm{L}$

476 AMPure beads (1.25X). The final library was eluted from the beads with $35 \mu \mathrm{L}$ elution buffer. $2 \times 150 \mathrm{bp}$

477 paired-end sequencing was performed using the Illumina HiSeq4000 system (Nationwide Children's

478 Hospital Institute for Genomic Medicine). Two independent replicates were performed for each sample,

479 with one replicate consisting of cells prepped from viral infection to sequencing.

480 CUT\&Tag (LSD1, H3K27ac, and Rb lgG)

481 Beads were resuspended in $100 \mu \mathrm{L}$ Dig-wash buffer and incubated with guinea pig anti-rabbit IgG

482 (Antibodies-Online ABIN101961) at a dilution of 1:100 on a rotator for 1 hour at $4^{\circ} \mathrm{C}$. After 3 washes with

483 Dig-wash buffer, beads were resuspended in $100 \mu \mathrm{L}$ Dig-300 buffer (20 mM HEPES-NaOH pH 7.5, 300

$484 \mathrm{mM} \mathrm{NaCl}, 0.5 \mathrm{mM}$ Spermidine, $0.01 \%$ Digitonin) with a 1:250 dilution of Protein A-Tn5 transposase fusion

485 protein (generously provided by the Henikoff lab). Samples were rotated for 1 hour at room temperature.

486 After 3 washes with Dig-300 buffer, beads were resuspended in $300 \mu \mathrm{L}$ Tagmentation buffer (Dig-300

487 buffer with $10 \mathrm{mM} \mathrm{MgCl}$ ) and incubated for 1 hour at $37^{\circ} \mathrm{C}$. Tagmentation was stopped by adding $10 \mu \mathrm{L}$

$488 \quad 0.5 \mathrm{M}$ EDTA, $3 \mu \mathrm{L} 10 \% \mathrm{SDS}$, and $2.5 \mu \mathrm{L} 20 \mathrm{mg} / \mathrm{mL}$ Proteinase $\mathrm{K}$ to each sample, vortexing $5 \mathrm{~s}$, and

489 incubating for 1 hour at $50^{\circ} \mathrm{C}$. DNA from samples was directly extracted using phenol-chloroform with

490 ethanol precipitation. Once ethanol-precipitated pellets were dry, pellets were resuspended in $30 \mu \mathrm{L} 10$

$491 \mathrm{mM}$ Tris- $\mathrm{Cl}$, pH 8 with $1 \mathrm{mM}$ EDTA and $1 / 400$ RNase $A$ and incubated at $37^{\circ} \mathrm{C}$ for $10 \mathrm{~min}$.

492 Libraries were amplified using primers as previously described. ${ }^{55} 21 \mu \mathrm{L}$ of DNA, and $2 \mu \mathrm{L}$ each of primer

$493(10 \mu \mathrm{M})$ were added to $25 \mu \mathrm{L}$ of NEBNext HiFi 2X PCR master mix and libraries were amplified as

494 follows: $72^{\circ} \mathrm{C}$ for $5 \mathrm{~min}, 98^{\circ} \mathrm{C}$ for $30 \mathrm{~s}, 15$ cycles of $98^{\circ} \mathrm{C}$ for $10 \mathrm{~s}$ and $63^{\circ} \mathrm{C}$ for $10 \mathrm{~s}, 72^{\circ} \mathrm{C}$ for $1 \mathrm{~min}$. After

495 the amplification a cleanup was performed by adding $55 \mu \mathrm{L}$ Agencourt AMPure XP magnetic beads

496 (Beckman Coulter, A63880) to the PCR reactions, incubating 15 minutes, and washing twice with $400 \mu \mathrm{L}$

$49780 \%$ ethanol, and eluting DNA with $25 \mu \mathrm{L}$ Tris- $\mathrm{Cl}$, pH $8.2 \times 150$ bp paired-end sequencing was performed

498 using the Illumina HiSeq4000 system (Nationwide Children's Hospital Institute for Genomic Medicine).

499 Two independent replicates were performed for each sample, with one replicate consisting of cells

500 prepped from viral infection to sequencing.

501 Bioinformatic analyses

502 For all samples the quality of raw fastq samples was evaluated using FastQC. ${ }^{56}$ Trim Galore! ${ }^{57}$ was then

503 used to trim both ChIP-seq, CUT\&RUN, and CUT\&Tag reads for adapter sequences and quality.

504 Trimmed reads were aligned to the human genome build hg19/GRCh37 using bowtie2. ChIP-seq reads

505 were aligned with the following parameters (default end-to-end alignment): bowtie2 --no-unal --no-mixed - 
506

507

508

509

510

511

512

513

514

515

516

517

518

519

520

521

522

523

524

525

526

527

528

529

530

531

532

533

534

535

536

537

538

539

540

-no-discordant --no-dovetail --phred 33 --q --I 10 --X 1000 --threads 16. CUT\&RUN reads were aligned with the following parameters: bowtie2 --no-unal --no-mixed --no-discordant --dovetail --phred 33 --q --I 10 --X 1000 --threads 16. Output SAM files were converted to BAM files, sorted, and indexed using samtools. ${ }^{58}$ Pybedtools ${ }^{59}$ was used to convert BAM files to BED files. To generate bigwig files for visualization, we first converted BED files to spike-in normalized (CUT\&RUN and CUT\&Tag) or readcount normalized (ChIP-seq) Bedgraph files. We then used the UCSC utility bedGraphToBigWig to generate BigWig files. Replicate samples were verified for high levels ( $>0.9$ for transcription factors and $>0.85$ for histone marks) of inter-sample correlation using the UCSC utility wigCorrelate. For CUT\&RUN and ChIP-seq, EWS/FLI, LSD1, H3K4me2, and H3K4me3, peaks were called using the default settings of MACS2 callpeak. ${ }^{60}$ For H3K4me1, peaks were called using the --broad setting of callpeak. H3K27ac peaks were called using csaw ${ }^{61}$ using a window of $150 \mathrm{bp}$, spacing of $50 \mathrm{bp}$, background signal binned into 2000 bp windows, and a 3-fold increase threshold over global background and an FDR of $<0.05$. For CUT\&Tag samples (LSD1, H3K27ac and Rb) peaks were called for each sample using the default settings of MACS2 without a control file specified. Then MACS2 bdgdiff with --d1 and --d2 flags used to specify spike-in factors was used to find regions of each sample (LSD1, H3K27ac) with greater signal than $\mathrm{Rb}$, as well as to compare samples in A673, EFKD, and wtEF cells directly. Tracks were generated in the Integrated Genome Browser. ChIPPeakAnno ${ }^{62}$ was used to analyze genomic distribution of peaks and, in concert with bedtools ${ }^{63}$, genome-wide overlaps between groups. HOMER ${ }^{64}$ was used to determine enriched motifs associated with different peaks utilizing the findMotifsGenome.pl script. GSEA ${ }^{37,65}$ was used to analyze functional association between peak-associated genes and EWS/FLI or LSD1 function. deepTools ${ }^{66}$ computeMatrix, plotProfile, and plotHeatmap were used to generate profile and heatmap figures for different groups of binding profiles. Ranked order of super-enhancers (ROSE) ${ }^{39,40}$ was used to identify super-enhancers and super-clusters.

\section{Quantification and Statistical Analysis}

Significance of experimental results was carried out using unpaired t-test for comparing two groups or one-way ANOVA (with multiple comparisons) for comparing three or more groups as appropriate.

Significance was determined as a $p<0.05$. These statistical tests were performed using GraphPad Prism 8. For GSEA significance was determined using a normalized enrichment score (NES). A result was significant if $|N E S|>1.5$. HOMER, MACS2 and csaw statistical defaults were used and are described elsewhere. ${ }^{60,61,64}$ For Venn diagram overlaps, $p$-values were determined using ChIPPeakAnno findOverlapOfPeaks.

\section{Data and Pipeline Availability}

Raw data, bigwigs, and peak calling results are available under the GEO accession: GSE144688

The quality, trimming, and alignment pipelines for single-end ChIP, CUT\&RUN, CUT\&Tag are available in Singularity containers and can be downloaded from Singularity Hub. 
Alternatively, the recipe files are available at https://github.com/ertheisen?tab=repositories.

\section{ACKNOWLEDGMENT}

546 We thank Dr. Ranajeet Saund for technical assistance. This research was supported in part by the High

547 Performance Computing Facility at the Abigail Wexner Research Institute at Nationwide Children's

548 Hospital.

\section{FUNDING}

551 This work was supported by the National Institutes of Health National Cancer Institute under U54

552 CA231641 (to S.L.L.) and R01 CA183776 (to S.L.L.); Pelotonia under a Postdoctoral Fellowship (to

553 E.R.T]; Alex's Lemonade Stand Foundation under a Young Investigator Award (to E.R.T.); and the 554 National Health and Medical Research Council CJ Martin Overseas Biomedical Fellowship under 555 APP1111032 to (K.I.P.).

558 S.L.L. declares a conflict of interest as a member of the advisory board for and an equity holder of

559 Salarius Pharmaceuticals. S.S. is a founder and equity holder of Salarius Pharmaceuticals. S.L.L. is also 560 a listed inventor on United States Patent No. US 7,939,253 B2, "Methods and compositions for the 561 diagnosis and treatment of Ewing's Sarcoma," and United States Patent No. US 8,557,532, "Diagnosis 562 and treatment of drug-resistant Ewing's sarcoma." This does not alter our adherence to Epigenetics 563 policies on sharing data and materials. 


\section{REFERENCES}

568

569

570

571

572

573

574

575

576

577

578

579

580

581

582

583

584

585

586

587

588

589

590

591

592

593

594

595

596

597

598

599

600

601

602

603

604

605

1. Burningham, Z., Hashibe, M., Spector, L. \& Schiffman, J. D. The Epidemiology of Sarcoma. Clin. Sarcoma Res. 2, 14 (2012).

2. Delattre, O. et al. Gene fusion with an ETS DNA-binding domain caused by chromosome translocation in human tumours. Nature 359, 162-165 (1992).

3. Turc-Carel, C., Philip, I., Berger, M. P., Philip, T. \& Lenoir, G. M. Chromosome study of Ewing's sarcoma (ES) cell lines. Consistency of a reciprocal translocation $\mathrm{t}(11 ; 22)(\mathrm{q} 24 ; \mathrm{q} 12)$. Cancer Genet. Cytogenet. 12, 1-19 (1984).

4. Turc-Carel, C. et al. Chromosomes in Ewing's sarcoma. I. An evaluation of 85 cases of remarkable consistency of t(11;22)(q24;q12). Cancer Genet. Cytogenet. 32, 229-238 (1988).

5. Boulay, G. et al. Cancer-Specific Retargeting of BAF Complexes by a Prion-like Domain. Cell 171, 163-178.e19 (2017).

6. May, W. A. et al. Ewing sarcoma 11;22 translocation produces a chimeric transcription factor that requires the DNA-binding domain encoded by FLI1 for transformation. Proc. Natl. Acad. Sci. U. S. A. 90, 5752-5756 (1993).

7. May, W. A. et al. The Ewing's sarcoma EWS/FLI-1 fusion gene encodes a more potent transcriptional activator and is a more powerful transforming gene than FLI-1. Mol. Cell. Biol. 13, 7393-7398 (1993).

8. Riggi, N. et al. EWS-FLI1 Utilizes Divergent Chromatin Remodeling Mechanisms to Directly Activate or Repress Enhancer Elements in Ewing Sarcoma. Cancer Cell 26, 668-681 (2014).

9. Sankar, S. et al. Mechanism and relevance of EWS/FLI-mediated transcriptional repression in Ewing sarcoma. Oncogene 32, 5089-5100 (2013).

10. Smith, R. et al. Expression profiling of EWS/FLI identifies NKX2.2 as a critical target gene in Ewing's sarcoma. Cancer Cell 9, 405-416 (2006).

11. Tomazou, E. M. et al. Epigenome Mapping Reveals Distinct Modes of Gene Regulation and Widespread Enhancer Reprogramming by the Oncogenic Fusion Protein EWS-FLI1. Cell Rep. 10, 1082-1095 (2015).

12. Gangwal, K., Close, D., Enriquez, C. A., Hill, C. P. \& Lessnick, S. L. Emergent Properties of EWS/FLI Regulation via GGAA Microsatellites in Ewing's Sarcoma. Genes Cancer 1, 177-187 (2010).

13. Gangwal, K. et al. Microsatellites as EWS/FLI response elements in Ewing's sarcoma. Proc. Natl. Acad. Sci. 105, 10149-10154 (2008).

14. Guillon, N. et al. The Oncogenic EWS-FLI1 Protein Binds In Vivo GGAA Microsatellite Sequences with Potential Transcriptional Activation Function. PLoS ONE 4, e4932 (2009).

15. Kwon, I. et al. Phosphorylation-Regulated Binding of RNA Polymerase II to Fibrous Polymers of LowComplexity Domains. Cell 155, 1049-1060 (2013).

16. Theisen, E. R. et al. Transcriptomic analysis functionally maps the intrinsically disordered domain of EWS/FLI and reveals novel transcriptional dependencies for oncogenesis. Genes Cancer 10, 21-38 (2019).

17. Sankar, S. et al. Reversible LSD1 Inhibition Interferes with Global EWS/ETS Transcriptional Activity and Impedes Ewing Sarcoma Tumor Growth. Clin. Cancer Res. 20, 4584-4597 (2014). 
606

607

608

609

610

611

612

613

614

615

616

617

618

619

620

621

622

623

624

625

626

627

628

629

630

631

632

633

634

635

636

637

638

639

640

641

642

643

644

18. Shi, Y. et al. Histone Demethylation Mediated by the Nuclear Amine Oxidase Homolog LSD1. Cell 119, 941-953 (2004).

19. Metzger, E. et al. LSD1 demethylates repressive histone marks to promote androgen-receptordependent transcription. Nature 437, 436-439 (2005).

20. Huang, J. et al. p53 is regulated by the lysine demethylase LSD1. Nature 449, 105-108 (2007).

21. Wang, J. et al. The lysine demethylase LSD1 (KDM1) is required for maintenance of global DNA methylation. Nat. Genet. 41, 125-129 (2009).

22. Yang, M. et al. Structural Basis for CoREST-Dependent Demethylation of Nucleosomes by the Human LSD1 Histone Demethylase. Mol. Cell 23, 377-387 (2006).

23. Whyte, W. A. et al. Enhancer decommissioning by LSD1 during embryonic stem cell differentiation. Nature 482, 221-225 (2012).

24. Hatzi, K. et al. Histone demethylase LSD1 is required for germinal center formation and BCL6-driven lymphomagenesis. Nat. Immunol. 20, 86 (2019).

25. Maiques-Diaz, A. et al. Enhancer Activation by Pharmacologic Displacement of LSD1 from GFI1 Induces Differentiation in Acute Myeloid Leukemia. Cell Rep. 22, 3641-3659 (2018).

26. Sugino, N. et al. A novel LSD1 inhibitor NCD38 ameliorates MDS-related leukemia with complex karyotype by attenuating leukemia programs via activating super-enhancers. Leukemia 31, 23032314 (2017).

27. Harris, W. J. et al. The histone demethylase KDM1A sustains the oncogenic potential of MLL-AF9 leukemia stem cells. Cancer Cell 21, 473-487 (2012).

28. Hayami, S. et al. Overexpression of LSD1 contributes to human carcinogenesis through chromatin regulation in various cancers. Int. J. Cancer 128, 574-586 (2011).

29. Kahl, P. et al. Androgen receptor coactivators lysine-specific histone demethylase 1 and four and a half LIM domain protein 2 predict risk of prostate cancer recurrence. Cancer Res. 66, 11341-11347 (2006).

30. Lim, S. et al. Lysine-specific demethylase 1 (LSD1) is highly expressed in ER-negative breast cancers and a biomarker predicting aggressive biology. Carcinogenesis 31, 512-520 (2010).

31. Schulte, J. H. et al. Lysine-specific demethylase 1 is strongly expressed in poorly differentiated neuroblastoma: implications for therapy. Cancer Res. 69, 2065-2071 (2009).

32. Bennani-Baiti, I. M., Machado, I., Llombart-Bosch, A. \& Kovar, H. Lysine-specific demethylase 1 (LSD1/KDM1A/AOF2/BHC110) is expressed and is an epigenetic drug target in chondrosarcoma, Ewing's sarcoma, osteosarcoma, and rhabdomyosarcoma. Hum. Pathol. 43, 1300-1307 (2012).

33. Schildhaus, H.-U. et al. Lysine-specific demethylase 1 is highly expressed in solitary fibrous tumors, synovial sarcomas, rhabdomyosarcomas, desmoplastic small round cell tumors, and malignant peripheral nerve sheath tumors. Hum. Pathol. 42, 1667-1675 (2011).

34. Pishas, K. I. et al. Therapeutic Targeting of KDM1A/LSD1 in Ewing Sarcoma with SP-2509 Engages the Endoplasmic Reticulum Stress Response. Mol. Cancer Ther. 17, 1902-1916 (2018).

35. Zhao, Z.-K. et al. Overexpression of lysine specific demethylase 1 predicts worse prognosis in primary hepatocellular carcinoma patients. World J. Gastroenterol. 18, 6651-6656 (2012). 
645

646

647

648

649

650

651

652

653

654

655

656

657

658

659

660

661

662

663

664

665

666

667

668

669

670

671

672

673

674

675

676

677

678

679

680

681

682

683

36. Sankar, S. et al. EWS and RE1-Silencing Transcription Factor Inhibit Neuronal Phenotype Development and Oncogenic Transformation in Ewing Sarcoma. Genes Cancer 4, 213-223 (2013).

37. Subramanian, A. et al. Gene set enrichment analysis: A knowledge-based approach for interpreting genome-wide expression profiles. Proc. Natl. Acad. Sci. 102, 15545-15550 (2005).

38. Boulay, G. et al. Epigenome editing of microsatellite repeats defines tumor-specific enhancer functions and dependencies. Genes Dev. (2018) doi:10.1101/gad.315192.118.

39. Lovén, J. et al. Selective Inhibition of Tumor Oncogenes by Disruption of Super-Enhancers. Cell 153, 320-334 (2013).

40. Whyte, W. A. et al. Master Transcription Factors and Mediator Establish Super-Enhancers at Key Cell Identity Genes. Cell 153, 307-319 (2013).

41. Kennedy, A. L. et al. Functional, chemical genomic, and super-enhancer screening identify sensitivity to cyclin D1/CDK4 pathway inhibition in Ewing sarcoma. Oncotarget 6, 30178-30193 (2015).

42. Johnson, K. M. et al. Role for the EWS domain of EWS/FLI in binding GGAA-microsatellites required for Ewing sarcoma anchorage independent growth. Proc. Natl. Acad. Sci. U. S. A. 114, 9870-9875 (2017).

43. Hnisz, D. et al. Super-Enhancers in the Control of Cell Identity and Disease. Cell 155, 934-947 (2013).

44. Agarwal, S. et al. LSD1/KDM1A Maintains Genome-wide Homeostasis of Transcriptional Enhancers. bioRxiv 146357 (2017) doi:10.1101/146357.

45. Kearns, N. A. et al. Functional annotation of native enhancers with a Cas9-histone demethylase fusion. Nat. Methods 12, 401-403 (2015).

46. Mendenhall, E. M. et al. Locus-specific editing of histone modifications at endogenous enhancers. Nat. Biotechnol. 31, 1133-1136 (2013).

47. Lee, C. et al. Lsd1 as a therapeutic target in Gfi1-activated medulloblastoma. Nat. Commun. 10, 332 (2019).

48. Cai, C. et al. Lysine-Specific Demethylase 1 Has Dual Functions as a Major Regulator of Androgen Receptor Transcriptional Activity. Cell Rep. 9, 1618-1627 (2014).

49. Sehrawat, A. et al. LSD1 activates a lethal prostate cancer gene network independently of its demethylase function. Proc. Natl. Acad. Sci. U. S. A. 115, E4179-E4188 (2018).

50. Melot, T. et al. Production and characterization of mouse monoclonal antibodies to wild-type and oncogenic FLI-1 proteins. Hybridoma 16, 457-464 (1997).

51. Lessnick, S. L., Dacwag, C. S. \& Golub, T. R. The Ewing's sarcoma oncoprotein EWS/FLI induces a p53-dependent growth arrest in primary human fibroblasts. Cancer Cell 1, 393-401 (2002).

52. Sankar, S. et al. A Novel Role for Keratin 17 in Coordinating Oncogenic Transformation and Cellular Adhesion in Ewing Sarcoma. Mol. Cell. Biol. 33, 4448-4460 (2013).

53. Kaya-Okur, H. S. et al. CUT\&Tag for efficient epigenomic profiling of small samples and single cells. Nat. Commun. 10, 1-10 (2019).

54. Skene, P. J. \& Henikoff, S. An efficient targeted nuclease strategy for high-resolution mapping of DNA binding sites. eLife 6, (2017). 
55. Buenrostro, J. D. et al. Single-cell chromatin accessibility reveals principles of regulatory variation. Nature 523, 486-490 (2015).

56. Andrews, S. FastQC: a quality control tool for high throughput sequence data.

57. Krueger, F. Trim Galore!: A wrapper tool around Cutadapt and FastQC to consistently apply quality and adapter trimming to FastQ files.

58. Tools (written in $C$ using htslib) for manipulating next-generation sequencing data: samtools/samtools. (samtools, 2019).

59. Dale, R. K., Pedersen, B. S. \& Quinlan, A. R. Pybedtools: a flexible Python library for manipulating genomic datasets and annotations. Bioinformatics 27, 3423-3424 (2011).

60. Feng, J., Liu, T., Qin, B., Zhang, Y. \& Liu, X. S. Identifying ChIP-seq enrichment using MACS. Nat. Protoc. 7, (2012).

61. Lun, A. T. L. \& Smyth, G. K. csaw: a Bioconductor package for differential binding analysis of ChIPseq data using sliding windows. Nucleic Acids Res. 44, e45 (2016).

62. Zhu, L. J. et al. ChIPpeakAnno: a Bioconductor package to annotate ChIP-seq and ChIP-chip data. BMC Bioinformatics 11, 237 (2010).

63. Quinlan, A. R. \& Hall, I. M. BEDTools: a flexible suite of utilities for comparing genomic features. Bioinformatics 26, 841-842 (2010).

64. Heinz, S. et al. Simple Combinations of Lineage-Determining Transcription Factors Prime cisRegulatory Elements Required for Macrophage and B Cell Identities. Mol. Cell 38, 576-589 (2010).

65. Mootha, V. K. et al. PGC-1a-responsive genes involved in oxidative phosphorylation are coordinately downregulated in human diabetes. Nat. Genet. 34, 267 (2003).

66. Ramírez, F. et al. deepTools2: a next generation web server for deep-sequencing data analysis. Nucleic Acids Res. 44, W160-W165 (2016). 


\section{TABLES AND FIGURES}

711 Figure 1. EWS/FLI colocalization with LSD1 is associated with gene activation

712 A) Venn diagram of EWS/FLI and LSD1 peaks as determined by ChIPPeakAnno; p-value calculated by

713 ChIPPeakAnno. B,C) IGB tracks showing coincidence of EWS/FLI and LSD1 near (B) LMO2 and (C)

714 SALL2. Tracks also show H3K27ac, H3K4me3, and mRNA in the A673 and EFKD conditions. D,E)

715 Genomic distributions of (D) LSD1 peaks in A673 cells and (E) EWS/FLI-LSD1 coincident peaks that are

716 common across all tested cell lines. F,G) GSEA results using promoter-proximal EWS/FLI-LSD1

717 coincident peaks ( $<5 \mathrm{~kb}$ to TSS) as the test set $(\mathrm{N}=102)$ and $(\mathrm{F}) \mathrm{EWS} / \mathrm{FLI}$ gene regulation or $(\mathrm{G})$ LSD1

718 gene regulation as the rank-ordered dataset. NES=normalized enrichment score. $|\mathrm{NES}|>1.5$ is significant.

$719 \mathrm{H}, \mathrm{I})$ Profile plots for signal intensity of LSD1, EWS/FLI, and H3K27ac within $2 \mathrm{~kb}$ of EWS/FLI-LSD1

720 coincident peaks in either A673 cells or EFKD cells as specified. Profile plots are separated into those

721 proximal to $(\mathrm{H})$ or distal to $(\mathrm{I})$ TSS. See also Supplementary Figures 1-7.

722

723 
bioRxiv preprint doi: https://doi.org/10.1101/2020.05.05.079533; this version posted May 7, 2020. The copyright holder for this preprint (which was not certified by peer review) is the author/funder, who has granted bioRxiv a license to display the preprint in perpetuity. It is made available under aCC-BY-NC-ND 4.0 International license.

A

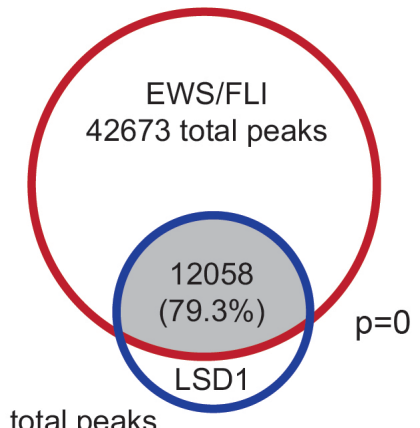

15202 total peaks

D

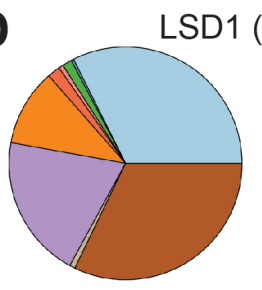

LSD1 (15202 peaks)

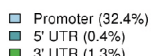

3. UTR (1.3\%)
1st Exon $(0.6 \%)$
Onther

Other Exon $(1.8 \%)$
ist Intron $(10.7 \%)$

宫 Other Intron (19.9\%)

믐 Downstream $(<=300)(0.8 \%$

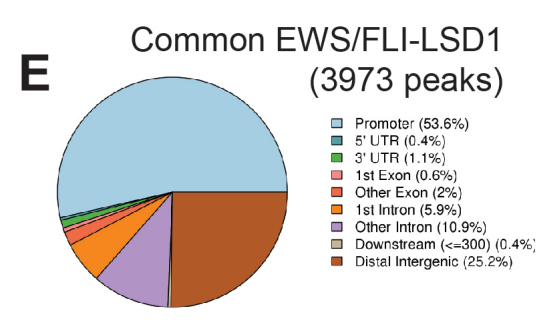

B

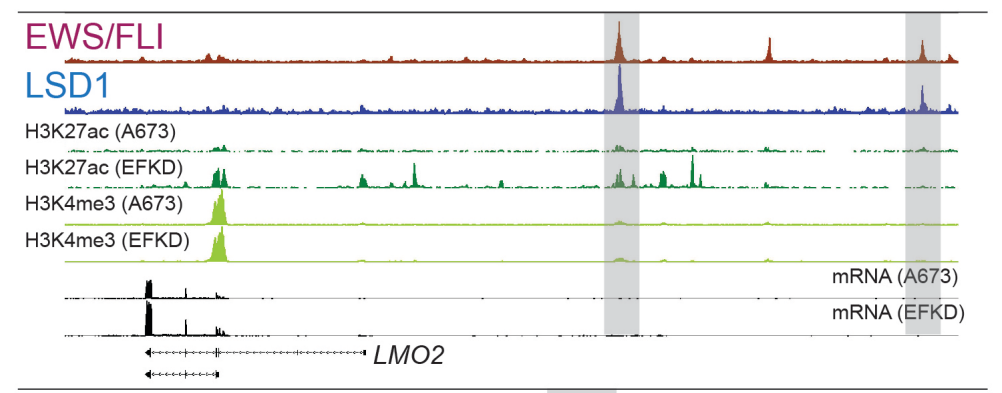

C

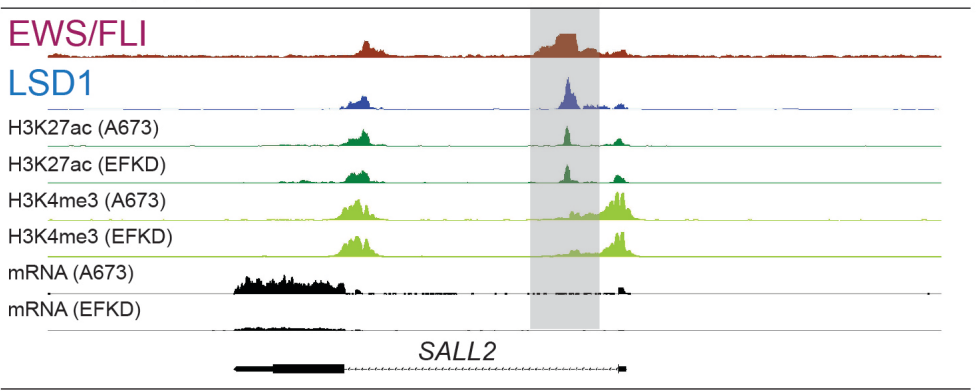

$\mathbf{F}$

Genes proximal to EWS/FLI-LSD1 peaks Rank-ordered list: EWS/FLI regulation

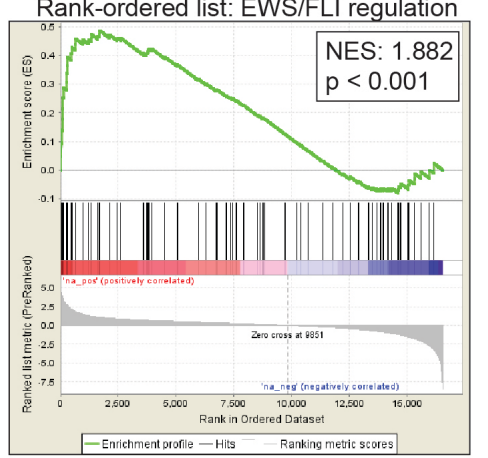

G

Genes proximal to EWS/FLI-LSD1 peaks Rank-ordered list: LSD1 regulation

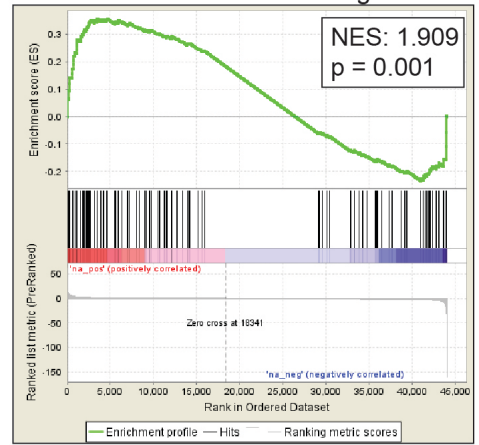

\section{H TSS-proximal peaks ( $<1 \mathrm{~kb} ; \mathrm{N}=1104)$}

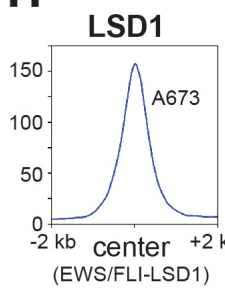

EWS/FLI

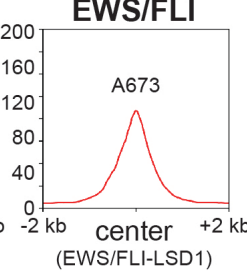

H3K27ac

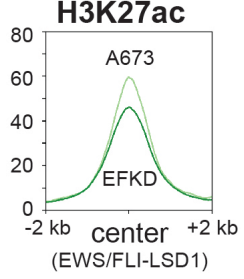

TSS-distal peaks (>1 kb; $N=1680$ )

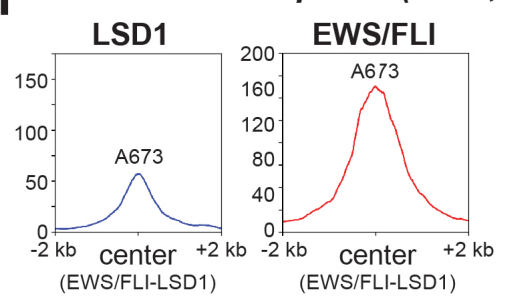

H3K27ac

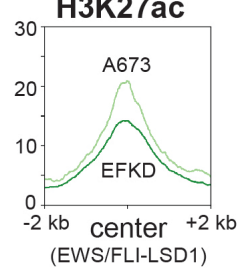


bioRxiv preprint doi: https://doi.org/10.1101/2020.05.05.079533; this version posted May 7, 2020. The copyright holder for this preprint (which was not certified by peer review) is the author/funder, who has granted bioRxiv a license to display the preprint in perpetuity. It is made available under aCC-BY-NC-ND 4.0 International license.

\section{Figure 2. LSD1 is enriched at EWS/FLI binding motifs}

727 A) Profile plots and heatmaps of EWS/FLI (red) and LSD1 (blue) within $3 \mathrm{~kb}$ of EWS/FLI peaks. GGAA-

728 microsatellite ( $\mu$ sat) peaks are represented in profile with a blue line and are the top panel in the

729 heatmap. Non-microsatellite (non- $\mu$ sat) peaks are represented in profile with a green line and are the

730 bottom panel in the heatmap. B) Top ranked result from HOMER de novo motif enrichment analysis with

731 significance value. See also Supplementary Figure 8.

732 
bioRxiv preprint doi: https://doi.org/10.1101/2020.05.05.079533; this version posted May 7, 2020. The copyright holder for this preprint (which was not certified by peer review) is the author/funder, who has granted bioRxiv a license to display the preprint in perpetuity. It is made available under aCC-BY-NC-ND 4.0 International license.

Figure 2

A

\section{EWS/FLI}
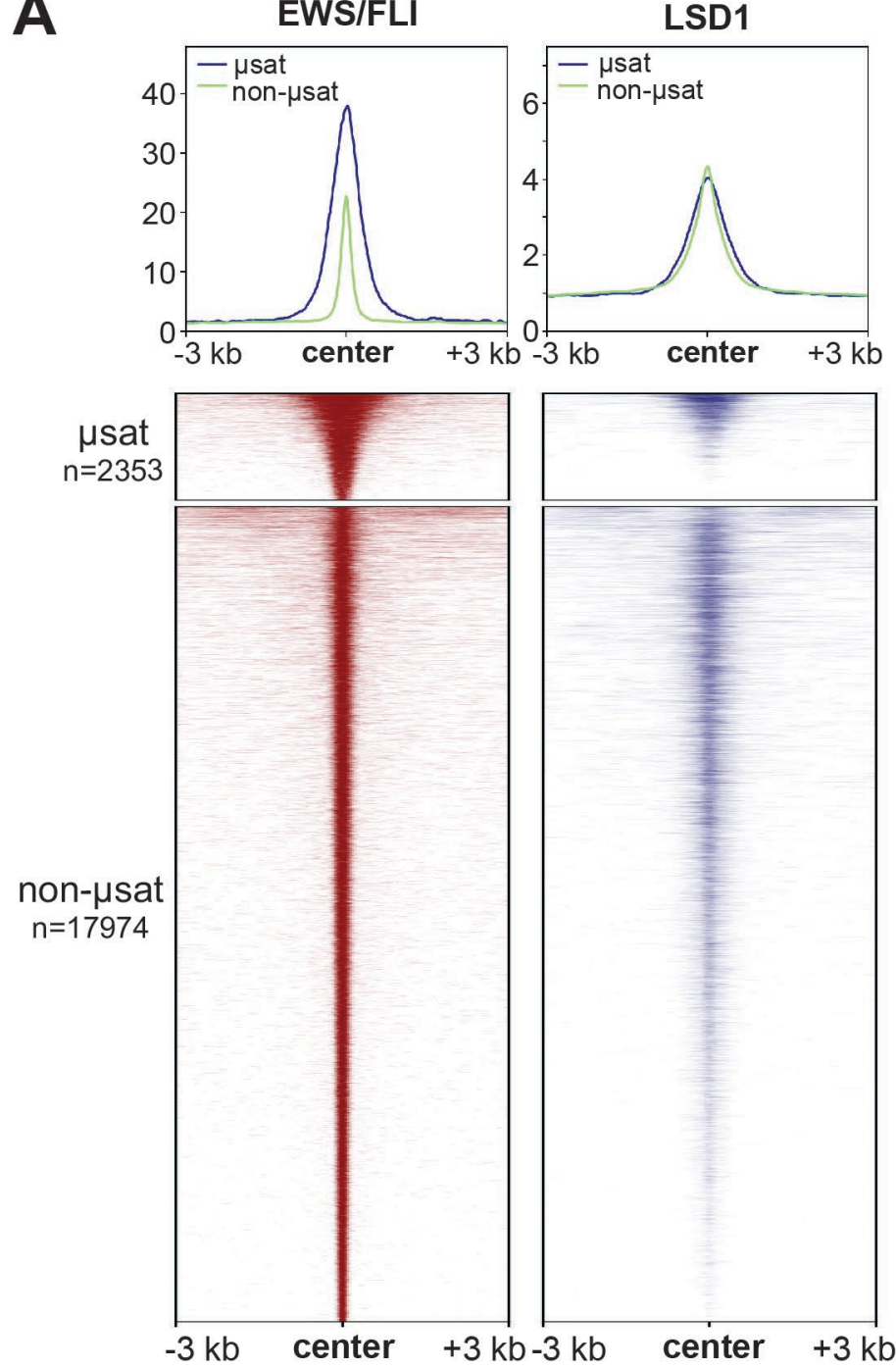

B ACCCCAACAGT

Fli1(ETS) p-value: 1E-388 
Figure 3. Super-enhancers in A673 cells are associated with both EWS/FLI and LSD1

736 A) Pie chart distribution of super-enhancers (SEs) in A673 cells by type of overlapped EWS/FLI-bound

737 motif. B) Base mean expression for genes associated with super- $(\mathrm{N}=615)$ and typical $(\mathrm{N}=6958)$

738 enhancers in A673 cells. Mean and SD are shown and $p$-values were determined using an unpaired t-

739 test. ${ }^{* * *} p<0.001$. C) Venn diagram of SEs in A673, EFKD, and wtEF cells as determined by

740 ChIPPeakAnno. D) Proportions of SEs present in A673 and EFKD cells sorted by the type of EWS/FLI-

741 bound motif overlapped by the SE. E) EWS/FLI-mediated differential expression for genes associated

742 with SEs in A673 cells sorted by the type of EWS/FLI-bound motif overlapped by the SE. Mean and SD

743 are shown and $p$-values were determined using one-way ANOVA with multiple comparison testing

$744 \quad\left({ }^{* * *} p<0.001,{ }^{* *} p<0.01,{ }^{*} p<0.05\right.$.) F) Pie chart distribution of SEs by type of EWS/FLI and LSD1 overlap.

$745 \mathrm{G}, \mathrm{H})(\mathrm{G}) \mathrm{H} 3 \mathrm{~K} 27$ ac score calculated from the ROSE algorithm and $(\mathrm{H})$ EWS/FLI-mediated differential

746 expression of nearby genes for SEs in A673 cells plotted by type of overlap with EWS/FLI and LSD1. EF-

747 L=EWS/FLI and LSD1 coincident peak, E/F=EWS/FLI only, L=LSD1 only. Mean and SD are shown. N for

748 differential expression and base mean is lower for those K27ac scores because not all genes near SEs

749 were detected by RNA-seq. P-values were determined using one-way ANOVA with multiple comparison

750 testing $\left({ }^{* * *} p<0.001,{ }^{* *} p<0.01,{ }^{*} p<0.05\right.$.) See also Supplementary Figures $9-11$ and Supplementary Tables

$751 \quad 1-14$. 
Figure 3
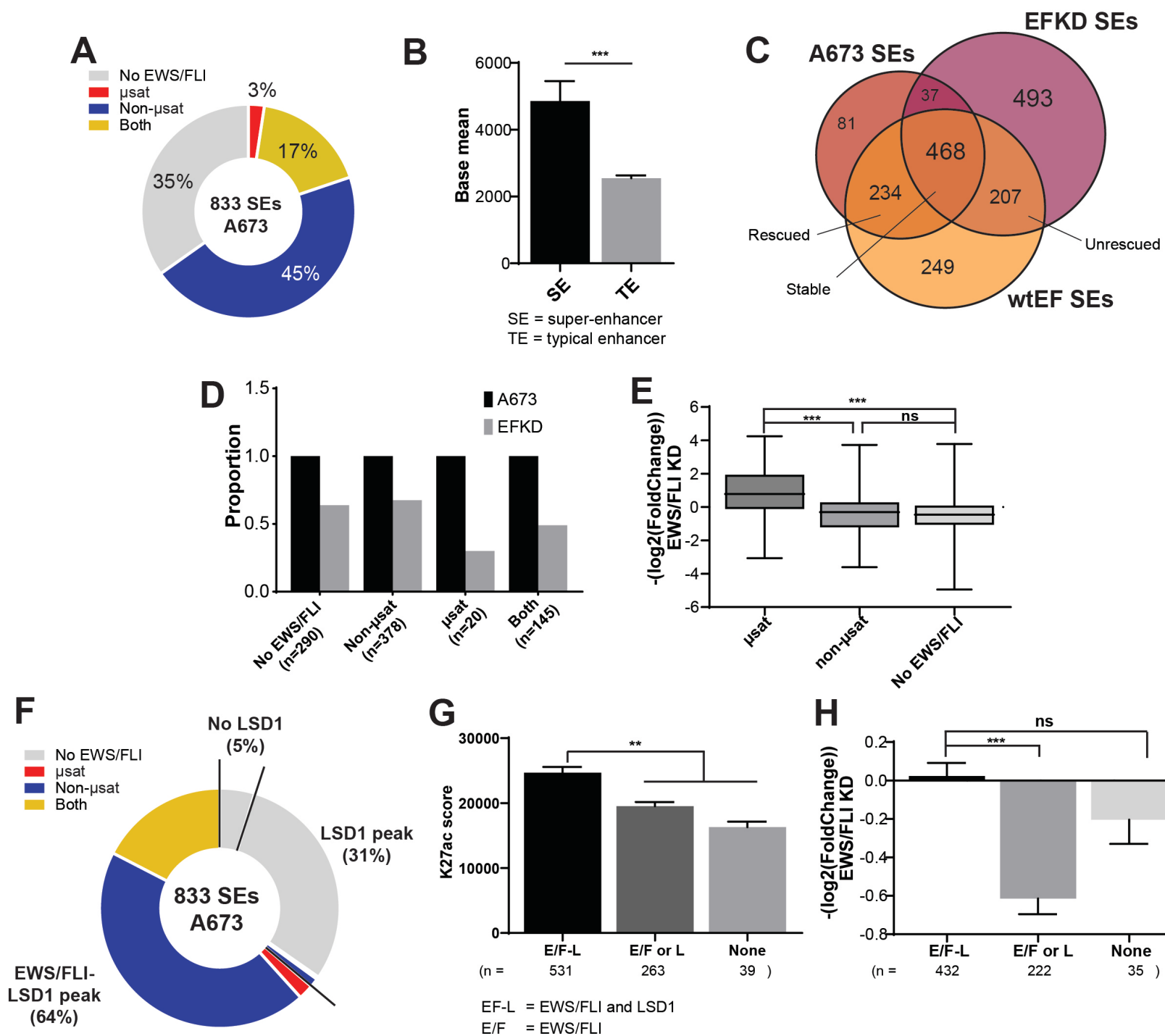

754
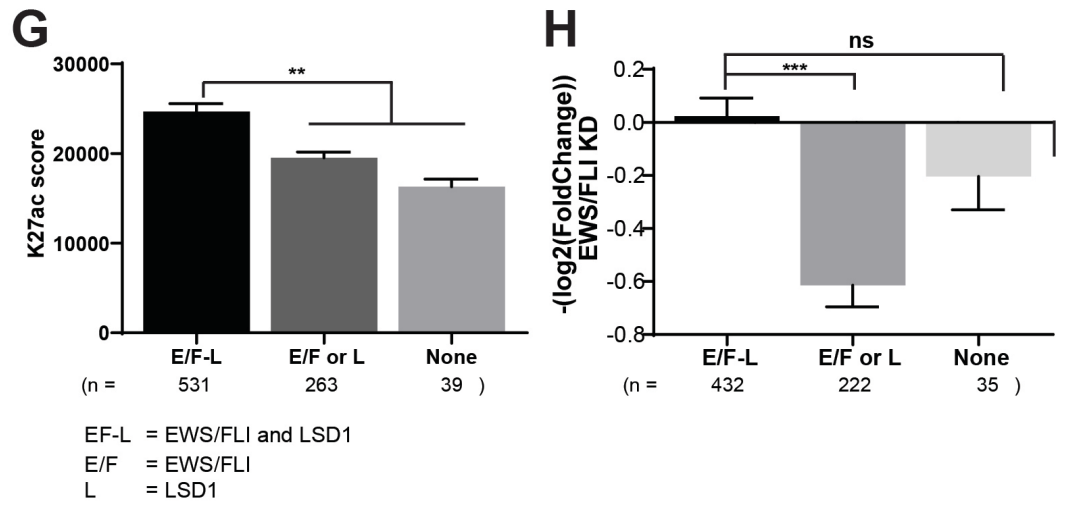

$E F-L=E W S / F L I$ and LSD

$\mathrm{E} / \mathrm{F}=\mathrm{EWS} / \mathrm{FL}$ 
bioRxiv preprint doi: https://doi.org/10.1101/2020.05.05.079533; this version posted May 7, 2020. The copyright holder for this preprint (which

was not certified by peer review) is the author/funder, who has granted bioRxiv a license to display the preprint in perpetuity. It is made available under aCC-BY-NC-ND 4.0 International license.

755 Figure 4. EWS/FLI alters the genome-wide occupancy of LSD1

$756 \mathrm{~A}, \mathrm{~B})$ IGB tracks showing EWS/FLI and LSD1 near (A) LMO2 and (B) SERPINE1. Tracks show LSD1 in

757 A673, EFKD, and wtEF cells and mRNA in the A673 and EFKD conditions. C) Venn diagram of LSD1

758 peaks in A673, EFKD, and wtEF cells as determined by ChIPPeakAnno. D) Bar charts showing the

759 dynamics of relative proportions of "stable" LSD1 peaks (detected in A673, EFKD and wtEF). E) Pie chart

760 distribution showing proportion of EWS/FLI-LSD1 coincident peaks with LSD1 binding dynamics as

761 compared to LSD1 localization in EFKD cells. See also Supplementary Figure 12. 
bioRxiv preprint doi: https://doi.org/10.1101/2020.05.05.079533; this version posted May 7, 2020. The copyright holder for this preprint (which was not certified by peer review) is the author/funder, who has granted bioRxiv a license to display the preprint in perpetuity. It is made available under aCC-BY-NC-ND 4.0 International license.

\section{Figure 4}

A

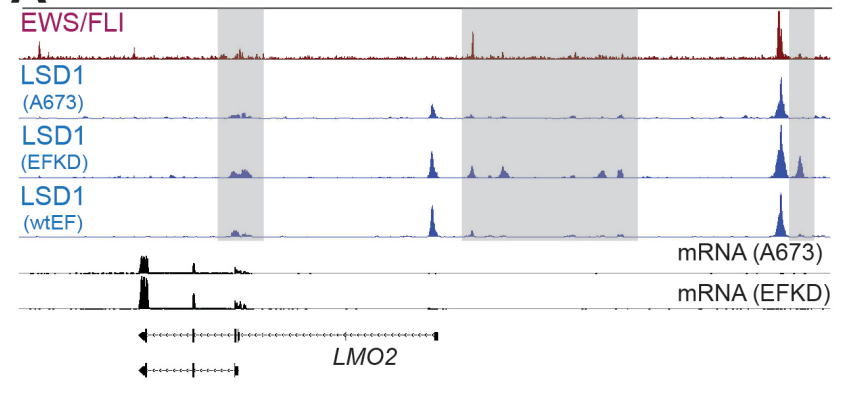

B

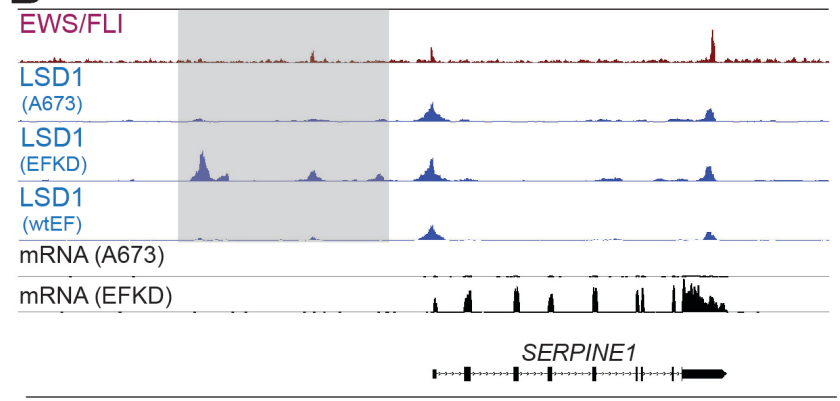

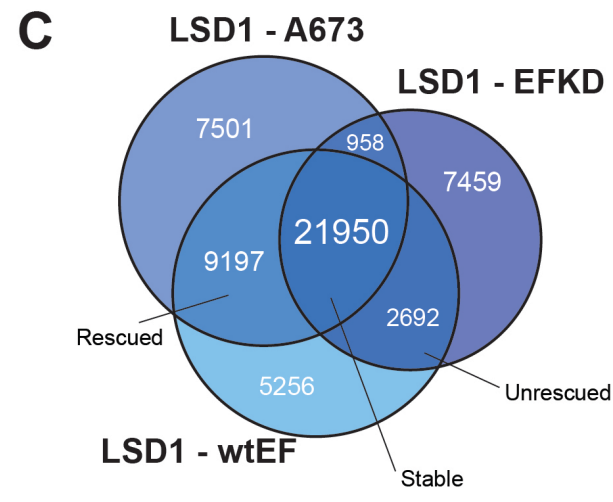

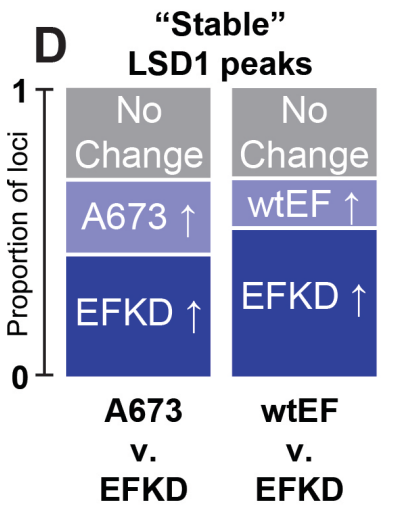


Figure 5. LSD1 binds in super-clusters that are disrupted by EWS/FLI

767 A) Venn diagram of LSD1 SCs in A673, EFKD, and wtEF cells B,C) Plotted output of the ROSE analysis

768 for LSD1 superclusters (SCs) in (B) A673 and (C) EFKD cells. D) IGB tracks showing coincidence of

769 EWS/FLI, LSD1, and H3K27ac in a SE and LSD1 SC near CCND1. Tracks show LSD1 and H3K27ac in

770 A673, EFKD, and wtEF conditions. E-G) Venn diagrams of SEs and LSD1 SCs in (E) A673 cells, (F)

771 EFKD cells, and (G) wtEF cells. Overlaps and p-values were determined by ChIPPeakAnno. H-J) GSEA

772 results using genes near $(H, I)$ LSD1 SCs in A673 cells $(N=427)$ or $(J)$ EFKD cells $(N=500)$ as the test set

773 and either LSD1 gene regulation in $A 673$ cells $(H)$ or EWS/FLI gene regulation $(I, J)$ as the rank-ordered

774 dataset. NES=normalized enrichment score. |NES|>1.5 is significant. K) Pie chart distribution showing the

775 number of leading edge LSD1 SCs (from J) that collapse in A673 cells. L) Pie chart distribution showing

776 the overlap of SEs in EFKD cells with different types of LSD1-binding. M,N) (M) H3K27ac score

777 calculated from the ROSE algorithm and (N) EWS/FLI-mediated differential expression of genes near SES

778 in EFKD cells plotted by type of overlap with LSD1. Mean and SD are shown. $N$ for $(N)$ is lower than (M)

779 because not all genes near SEs were detected by RNA-seq. $p$-values were determined using one-way

780 ANOVA with multiple comparison testing $\left({ }^{* * *} p<0.001,{ }^{* *} p<0.01,{ }^{*} p<0.05\right.$.) See also Supplementary

781 Figures 13-14 and Supplementary Tables 2, 4, 6, and 15-20. 
bioRxiv preprint doi: https://doi.org/10.1101/2020.05.05.079533; this version posted May 7, 2020. The copyright holder for this preprint (which was not certified by peer review) is the author/funder, who has granted bioRxiv a license to display the preprint in perpetuity. It is made available under aCC-BY-NC-ND 4.0 International license.

Figure 5
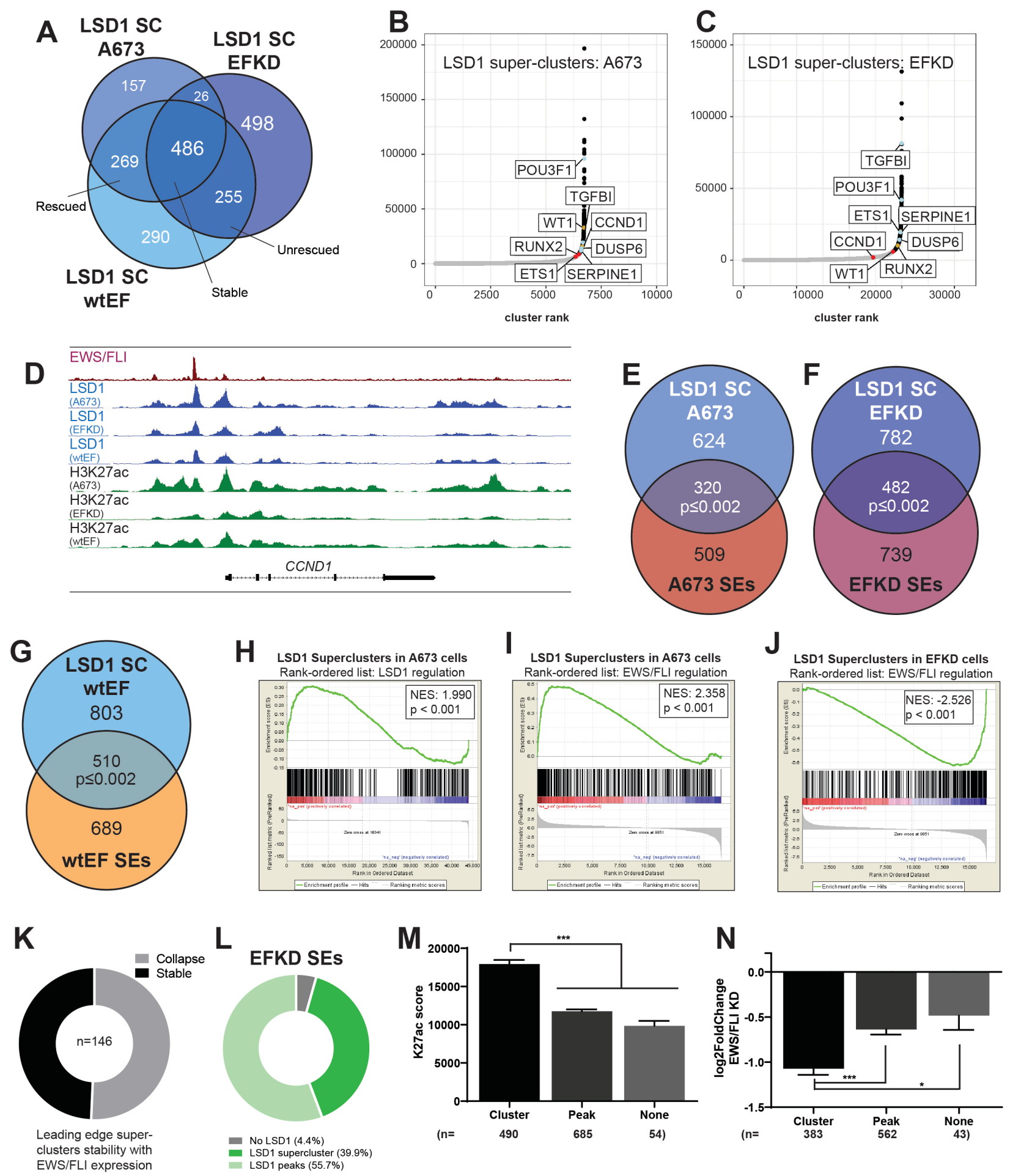


\section{Figure 6. LSD1 is tightly linked to the shifting enhancer landscape in Ewing sarcoma}

787 A) Model figure showing how EWS/FLI remodels the enhancer landscape and the role of LSD1 in this

788 remodeling. The top panels depict enhancer states found in a precursor cell and the bottom panels

789 represent a Ewing sarcoma cell. Panel (i) shows chromatin remodeling which results in de novo enhancer

790 formation at GGAA- $\mu$ sats. Panel (ii) shows chromatin remodeling which occurs at enhancers bound by

791 LSD1 with another ETS family member in precursor cells. These enhancers are hijacked by EWS/FLI.

792 Panel (iii) shows supercluster and enhancer collapse which occurs at enhancers with LSD1 superclusters

793 in precursor cells with establishment of an LSD1-decorated supercluster driven by EWS/FLI. The number

794 of Polll molecules by any gene correlates to the level of transcription from those genes. 
bioRxiv preprint doi: https://doi.org/10.1101/2020.05.05.079533; this version posted May 7, 2020. The copyright holder for this preprint (which was not certified by peer review) is the author/funder, who has granted bioRxiv a license to display the preprint in perpetuity. It is made available under aCC-BY-NC-ND 4.0 International license.

\section{Figure 6}

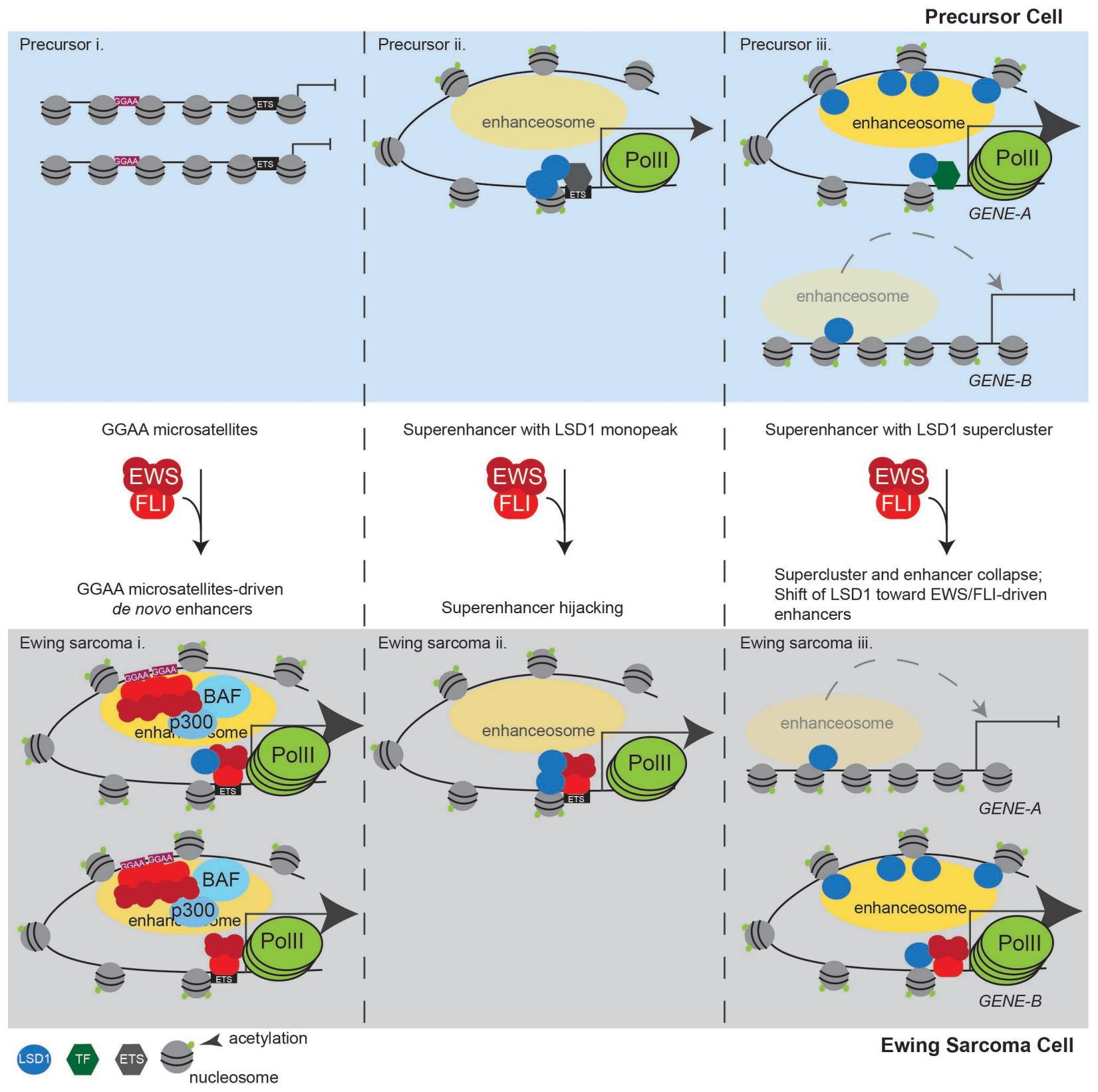




\section{SUPPLEMENTAL FIGURES}

\section{Supplementary Figure 1}

A) Genomic distributions of EWS/FLI-LSD1 coincident peaks in A673 cells. B-D) Venn diagram of EWS/FLI and LSD1 peaks in (B) EWS-502, (C) SK-N-MC, and (D) TC71 cells as determined by ChIPPeakAnno; p-value calculated by ChIPPeakAnno. E-G) Genomic distributions of LSD1 peaks and EWS/FLI-LSD1 coincident peaks in (E) EWS-502, (F) SK-N-MC, and (G) TC71 cells.

\section{Supplementary Figure 2}

$A, B)$ Venn diagram of $(A) E W S / F L I$ and $(B)$ LSD1 peaks in all cell lines tested as determined by ChIPPeakAnno. C) Venn diagram of EWS/FLI and LSD1 peaks common across all cell lines as determined by ChIPPeakAnno. D) Genomic distributions of LSD1 peaks common across cell lines.

\section{Supplementary Figure 3}

A-E) Venn diagram of EWS/FLI and LSD1 peaks that pass an 8-fold enrichment cutoff in (A) A673 cells, (B) EWS-502 cells, (C) SK-N-MC cells, and (D) TC71 cells as determined by ChIPPeakAnno; $p$-value calculated by ChIPPeakAnno. (E) shows the overlap between common EWS/FLI and common LSD1 peaks.

\section{Supplementary Figure 4}

A-E) Genomic distributions of LSD1 peaks and EWS/FLI-LSD1 coincident peaks which pass an 8-fold enrichment in (A) A673, (B) EWS-502, (C) SK-N-MC, and (D) TC71 cells. (E) depicts genomic distribution of peaks common across cell lines.

\section{Supplementary Figure 5}

A,B) IGB tracks showing coincidence of EWS/FLI and LSD1 near EWS/FLI-repressed gene DUSP6 (A) and EWS/FLI-activated gene HES1 (B). Tracks also show H3K27ac, H3K4me3, and mRNA in the A673 and EWS/FLI-depleted (EFKD) conditions. C-E) Genomic tracks showing localization of LSD1 and EWS/FLI near (C) LMO2, (D) SALL2, and (E) DUSP6 in all tested cell lines.

\section{Supplementary Figure 6}

A-H) GSEA results using promoter-proximal EWS/FLI-LSD1 coincident peaks ( $<5 \mathrm{~kb}$ to TSS) in different cell lines $(A-F)$ or common to all cell lines $(G, H)$ as the test and $(A-C, G) E W S / F L I$ gene regulation or (D$\mathrm{F}, \mathrm{H}) \mathrm{LSD} 1$ gene regulation as the rank-ordered dataset. NES=normalized enrichment score. $|\mathrm{NES}|>1.5$ is significant. EWS-502: $n=164$. SK-N-MC: $n=182$. TC71: $n=87$. Common: $n=123$

\section{Supplementary Figure 7}

A,B) Profile plots for signal intensity of H3K4me1, H3K4me2, and H3K4me3 within $3 \mathrm{~kb}$ of EWS/FLI-LSD1 coincident peaks in either A673 cells or EFKD as specified. Profile plots are separated into those regions either proximal to $(A, n=1104)$ or distal to $(B, n=1680)$ TSS. 


\section{Supplementary Figure 8}

840

841

842

843

844

845

846

847

848

849

850

851

852

853

854

855

856

857

858

859

860

861

862

863

864

865

866

\section{7}

868

869

870

871

872

\section{3}

874

875

876

877

878

A-C) Profile plots and heatmaps of EWS/FLI (red) and LSD1 (blue) within $3 \mathrm{~kb}$ of EWS/FLI peaks in (A) EWS-502, (B) SK-N-MC, and (C) TC71 cells. GGAA-microsatellite ( $\mu$ sat) peaks are represented in profile with a blue line and are the top panel in the heatmap. Non-microsatellite (non- $\mu s a t)$ peaks are represented in profile with a green line and are the bottom panel in the heatmap. D) Top two ranked results from HOMER de novo motif enrichment analysis in different cells with significance value.

\section{Supplementary Figure 9; related to Supplementary Tables 1-6}

A) Plotted output of the ROSE analysis for super-enhancers in A673 cells. B,C) Western blot validation of EWS/FLI KD in EFKD cells and rescue with 3XFLAG-EWS/FLI in wtEF cells in (B) replicate 1 and (C) replicate 2. Ectopic EWS/FLI was introduced following RNAi-mediated depletion of EWS/FLI using iEF-2 or an iLuc (negative control) construct. D,E) Plotted output of the ROSE analysis for super-enhancers in (D) EFKD and (E) wtEF cells. F) Base mean expression of genes associated with super-enhancers in A673 cells separated by the type of overlap with EWS/FLI and LSD1. E/F-L = EWS/FLI and LSD1, EF = EWS/FLI only, L = LSD1 only, or None. Mean and SD are shown and P-values were determined using one-way ANOVA with multiple comparison testing. No significant differences were detected.

\section{Supplementary Figure 10; related to Supplementary Tables 7-14}

A-D) Pie chart distribution of super-enhancers (SEs) in (A)A673, (B) EWS-502, (C) SK-N-MC, and (D) TC71 cells (CUT\&RUN) by type of overlapped EWS/FLI-bound motif. E-H) Pie chart distribution of SEs in (E) A673, (F) EWS-502, (G) SK-N-MC, and (H) TC71 cells (CUT\&RUN) by type of EWS/FLI and LSD1 overlap. I-L) H3K27ac score calculated from the ROSE algorithm for SEs in (I) A673, (J) EWS-502, (K) SK-N-MC, and (L) TC71 cells (CUT\&RUN) plotted by type of overlap with EWS/FLI and LSD1. E/F$\mathrm{L}=\mathrm{EWS} / \mathrm{FLI}$ and LSD1 coincident peak, $\mathrm{EF}=\mathrm{EWS} / \mathrm{FLI}$ only, $\mathrm{L}=\mathrm{LSD} 1$ only. Mean and SD are shown and $\mathrm{p}-$ values were determined using one-way ANOVA with multiple comparison testing $\left({ }^{* * *} p<0.001,{ }^{* *} p<0.01\right.$, ${ }^{*} p<0.05$.) $\mathrm{N}$ for differential expression is lower for those K27ac scores because not all genes near SEs were detected by RNA-seq.

\section{Supplementary Figure 11; related to Supplementary Tables 8, 10, 12, 14}

A-D) GSEA results using genes near SEs with an EWS/FLI-LSD1 coincident peak in (A) A673 cells (CUT\&RUN, $n=319),(B)$ EWS-502 cells $(n=545),(C)$ SK-N-MC cells $(n=491)$, and (D) TC71 cells $(n=251)$ as the test set and LSD1 gene regulation in A673 cells as the rank-ordered dataset. NES $=$ normalized enrichment score. $|\mathrm{NES}|>1.5$ is significant.

\section{Supplementary Figure 12}

IGB tracks showing EWS/FLI and LSD1 near SERPINE1, AP1S1, VGF, and NAT16. Tracks show the sensitivity of CUT\&Tag to detect changes in LSD1 levels between A673, EFKD, and wtEF cells, with a region over SERPINE1 showing increased LSD1 with EWS/FLI depletion, and another region near VGF showing decreased LSD1 with EWS/FLI depletion. 


\section{Supplementary Figure 13; related to Supplementary Tables 1-6, 15-20}

880 A) Plotted output of the ROSE analysis for LSD1 superclusters (SCs) in wtEF cells. B-D) IGB tracks 881 showing coincidence of EWS/FLI, LSD1, and H3K27ac in a super-enhancer and LSD1 super-cluster near 882 DUSP6 (B), ETS1 (C), and TGFBI (D). Tracks show LSD1 and H3K27ac in A673, EFKD, and wtEF 883 conditions. In $(\mathrm{C})$ the super-enhancer and super-cluster are only present in EFKD cells.

884

885 Supplementary Figure 14; related to Supplementary Tables 2, 4, and 6

886 A,B) Pie chart distribution showing the overlap of SEs in (A) A673 and (B) wtEF cells with different types

887

888

889

890

891

892

893

894 of LSD1-binding. C,D) H3K27ac score calculated from the ROSE algorithm for (C) A673 and (D) wtEF cells plotted by type of overlap with LSD1. E-G) Base mean expression of genes associated with superenhancers in (E) A673, (F) EFKD, and (G) wtEF cells separated by the type of overlap with LSD1. H,I) EWS/FLI-mediated differential expression of genes near SEs in (H) A673 and (I) wtEF cells plotted by type of overlap with LSD1. Mean and SD are shown and $p$-values were determined using one-way ANOVA with multiple comparison testing $\left({ }^{* * *} p<0.001,{ }^{* *} p<0.01,{ }^{*} p<0.05\right)$. $\mathrm{N}$ for differential expression and base mean is lower for those K27ac scores because not all genes near SEs were detected by RNAseq. J) Pie chart distribution showing the number of LSD1 SCs in LSD1 SC-containing SEs unique to 896 


\section{Supplementary Figure 1}
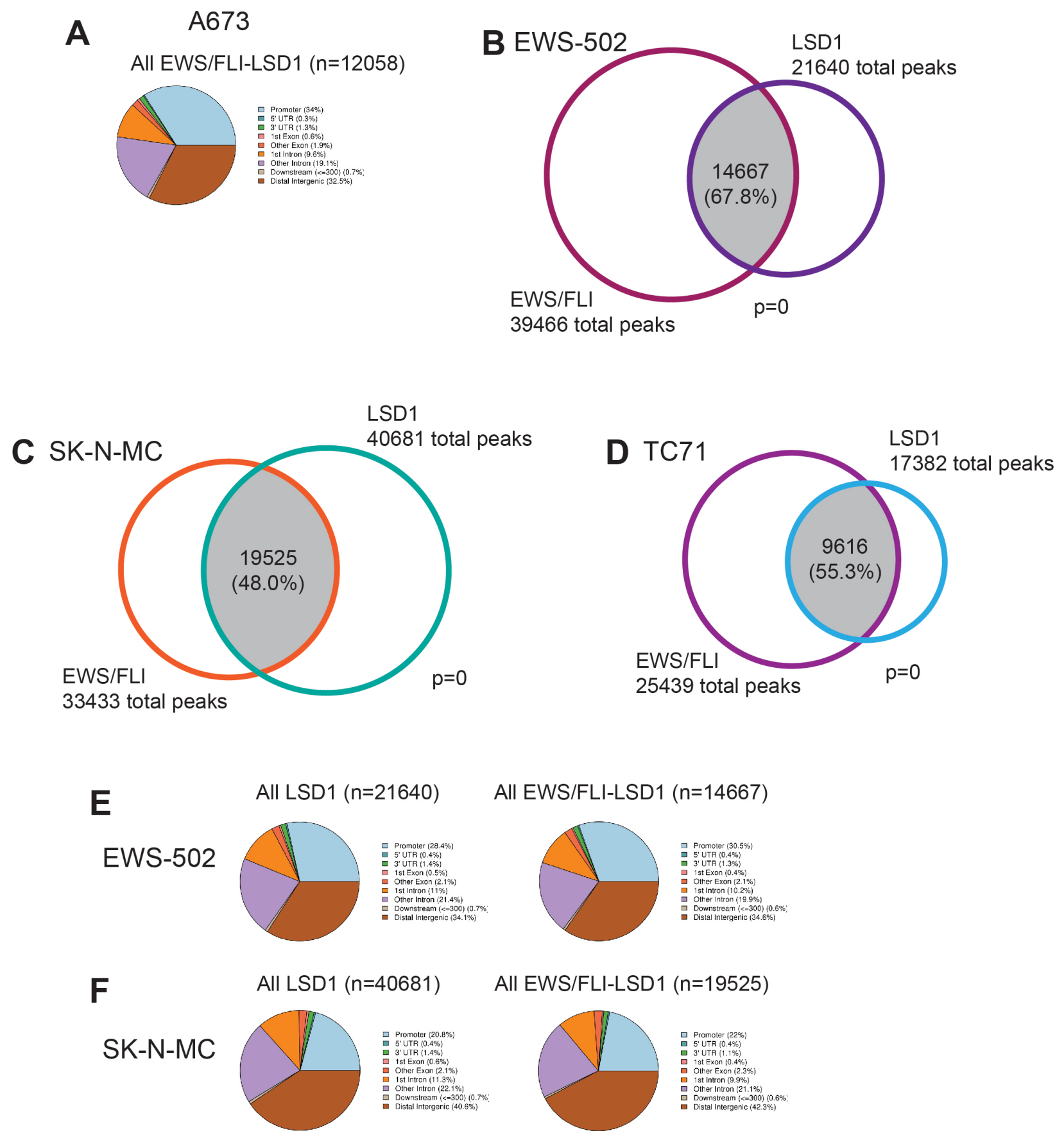

G All LSD1 (n=17382) All EWS/FLI-LSD1 (n=9616)
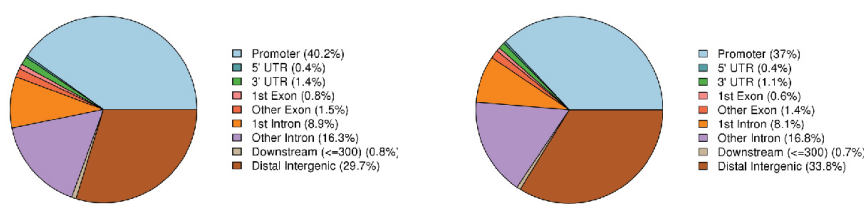
bioRxiv preprint doi: https://doi.org/10.1101/2020.05.05.079533; this version posted May 7, 2020. The copyright holder for this preprint (which

was not certified by peer review) is the author/funder, who has granted bioRxiv a license to display the preprint in perpetuity. It is made available under aCC-BY-NC-ND 4.0 International license.

\section{Supplementary Figure 2}

A A673: 42763 peaks $10300 \mathrm{EWS} / \mathrm{FLI}$ peaks

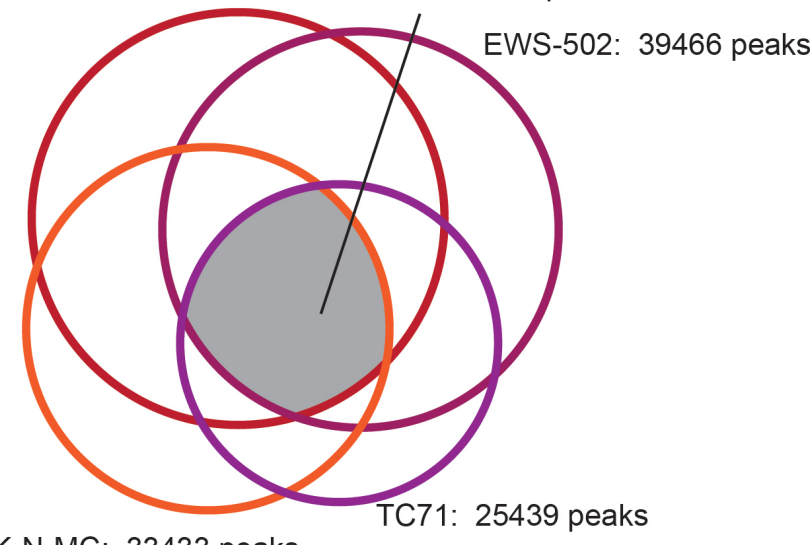

SK-N-MC: 33433 peaks

901

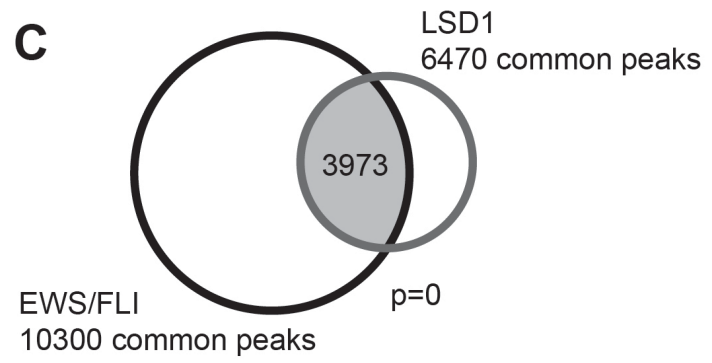

B

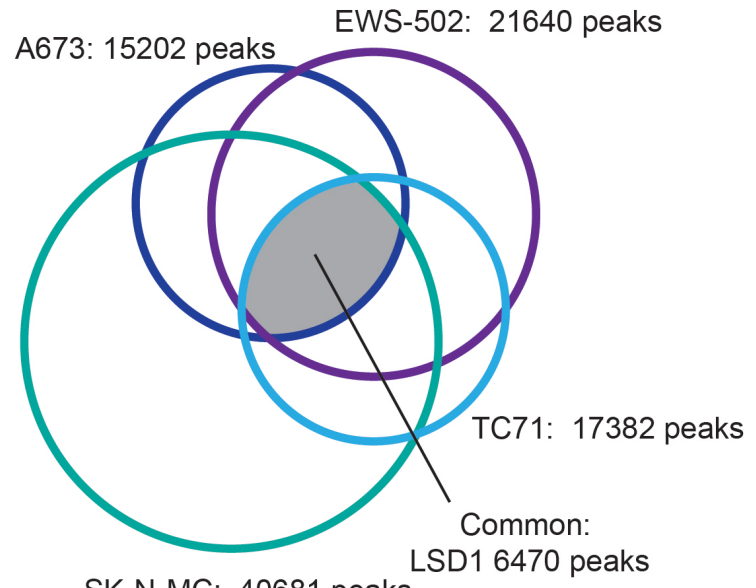

SK-N-MC: 40681 peaks

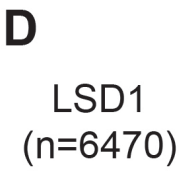

902 


\section{Supplementary Figure 3}

\section{Peaks with $>8 \mathrm{FC}$ enrichment over background}
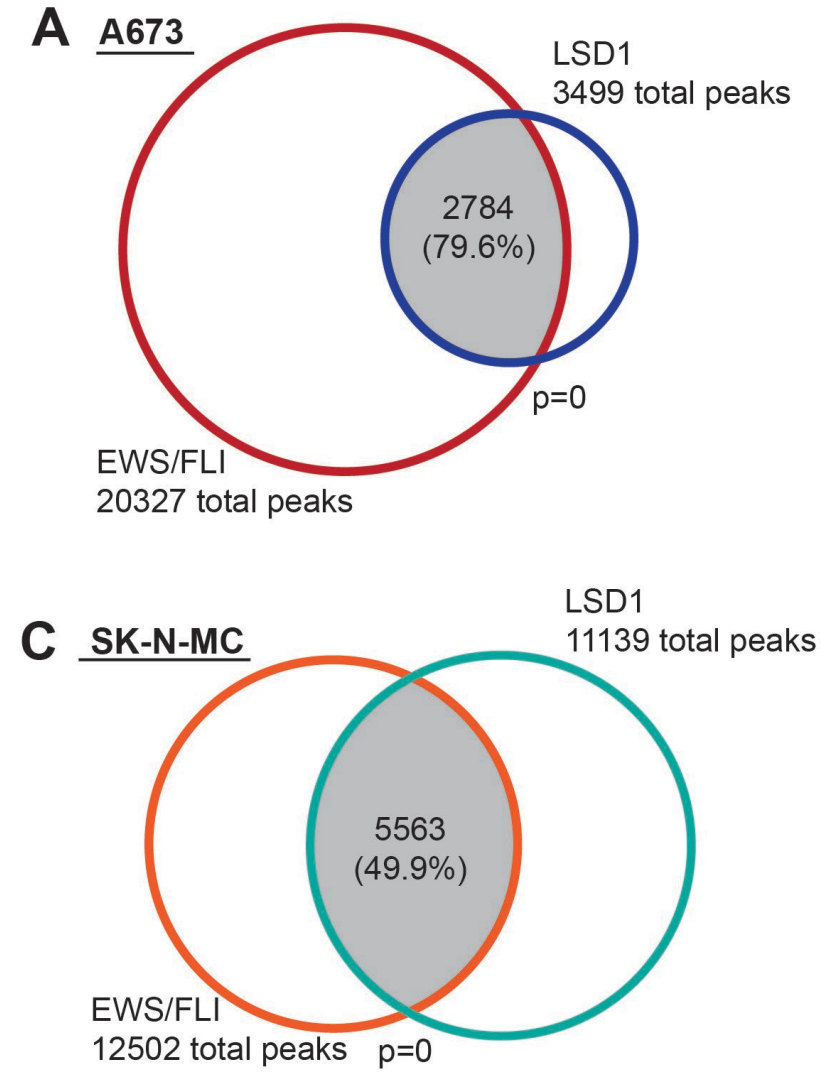
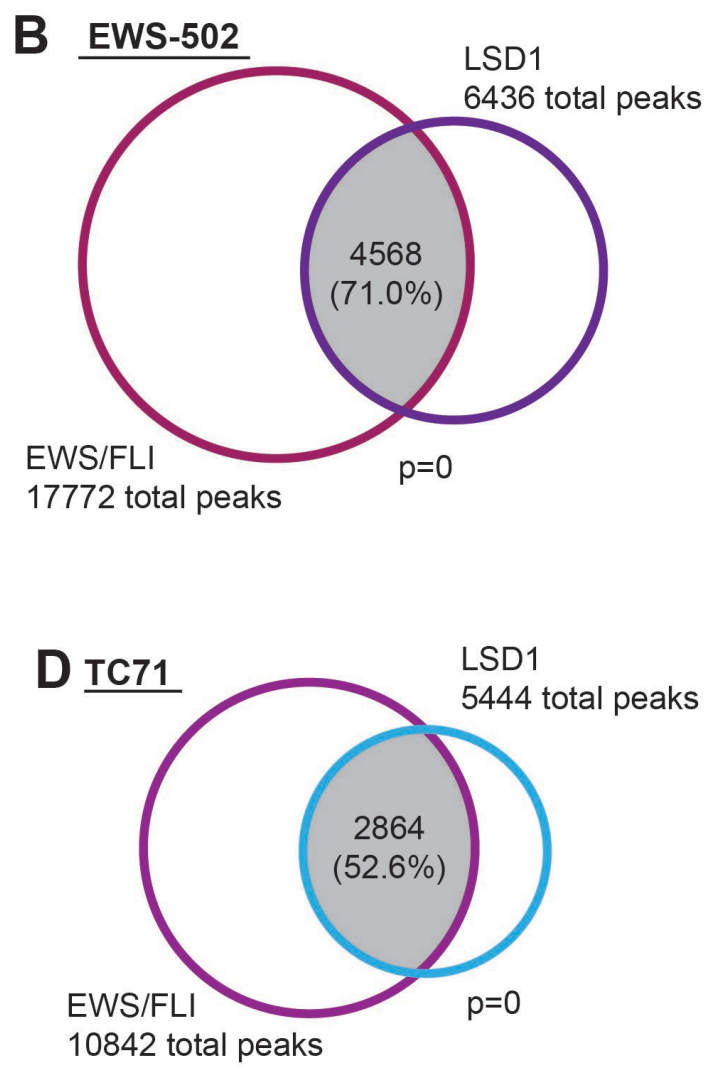

E 1746 common peaks

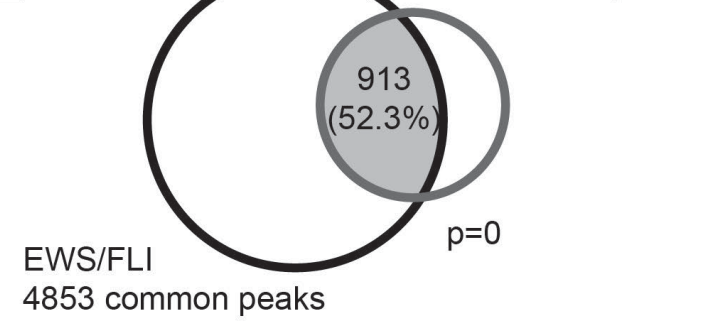




\section{Supplementary Figure 4}

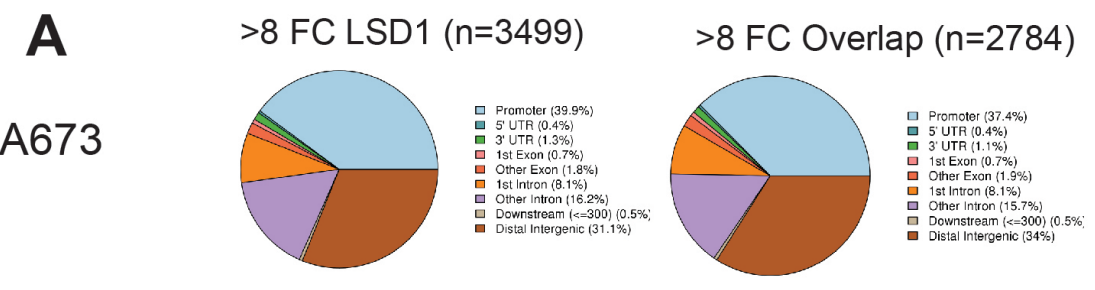

B

EWS-502

$>8$ FC LSD1 $(n=6436)$

$$
>8 \text { FC Overlap }(n=4568)
$$
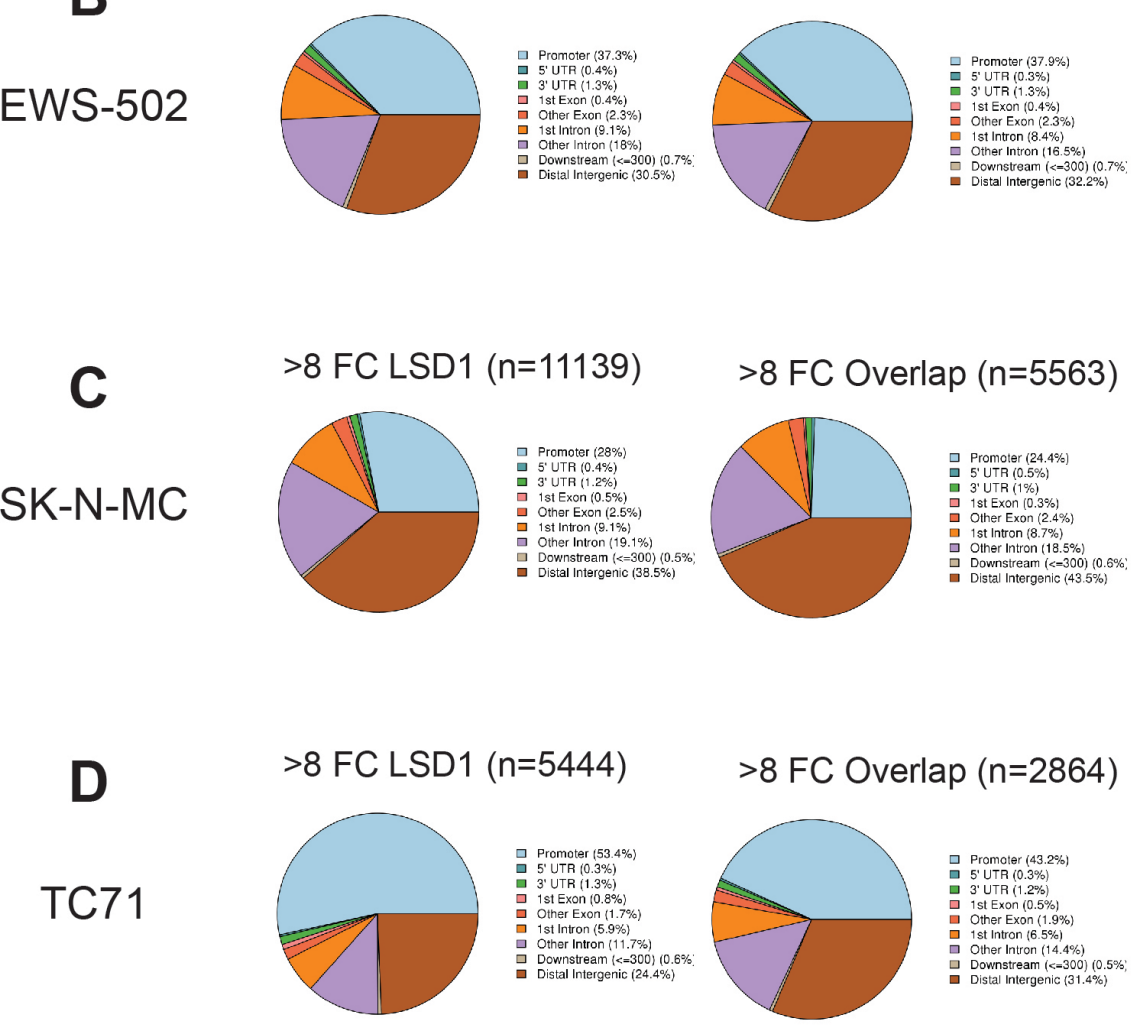

$(n=5444)$

$>8$ FC Overlap $(n=2864)$
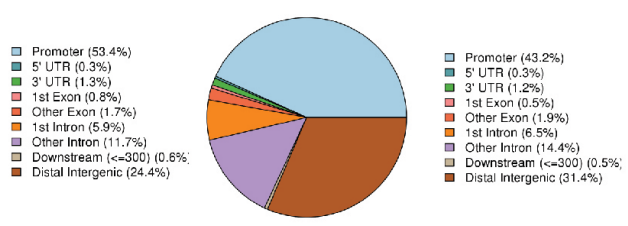

E

$>8$ FC LSD1 $(n=1746)$

>8 FC Overlap $(n=913)$

Common
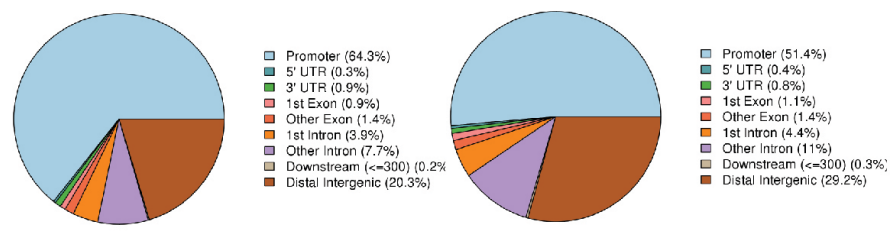
bioRxiv preprint doi: https://doi.org/10.1101/2020.05.05.079533; this version posted May 7, 2020. The copyright holder for this preprint (which was not certified by peer review) is the author/funder, who has granted bioRxiv a license to display the preprint in perpetuity. It is made available under aCC-BY-NC-ND 4.0 International license.

\section{Supplementary Figure 5}

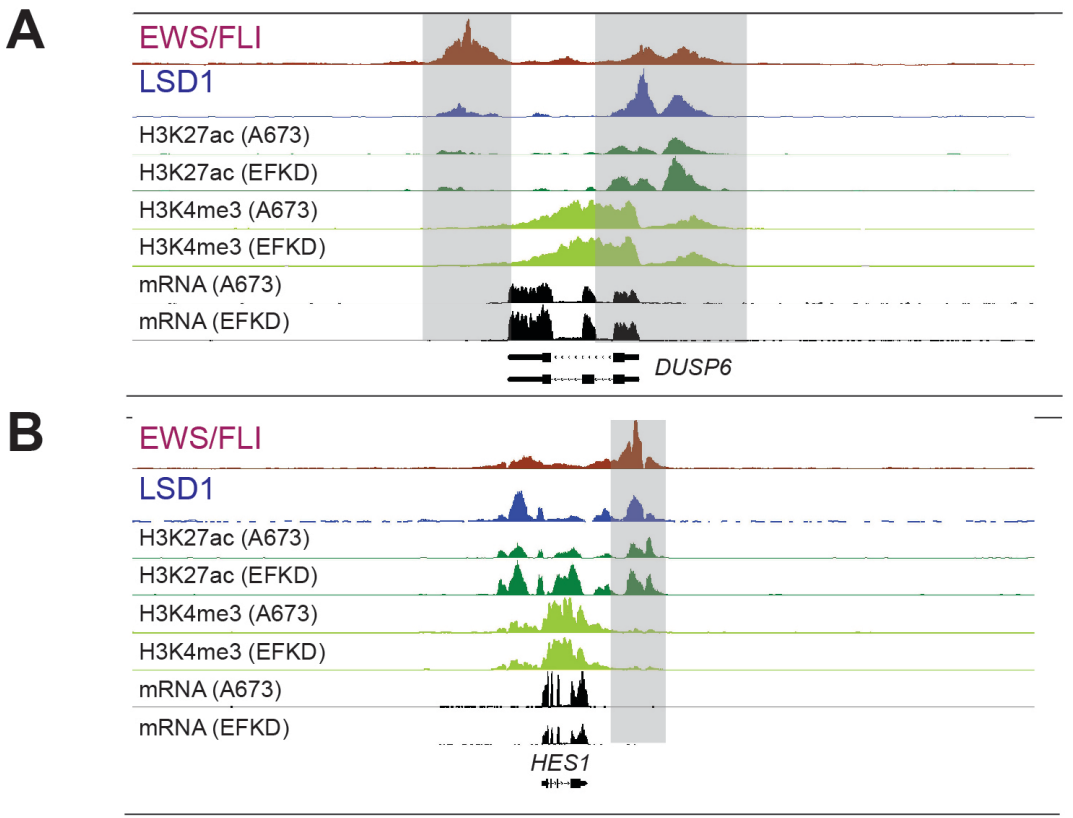

\begin{tabular}{|c|c|c|c|}
\hline \multirow{2}{*}{ A673 } & EWS/FLI & 1 & $1 \quad 1$ \\
\hline & LSD1 & 1 & \\
\hline \multirow{2}{*}{ EWS502 } & EWS/FLI & 1 & \\
\hline & LSD1 & $d$ & \\
\hline \multirow{2}{*}{ SKNMC } & EWS/FLI & $A$ & \\
\hline & LSD1 & 1 & \\
\hline \multirow{2}{*}{ TC71 } & EWS/FLI & $\ldots$ & \\
\hline & LSD1 & 1 & \\
\hline
\end{tabular}

D

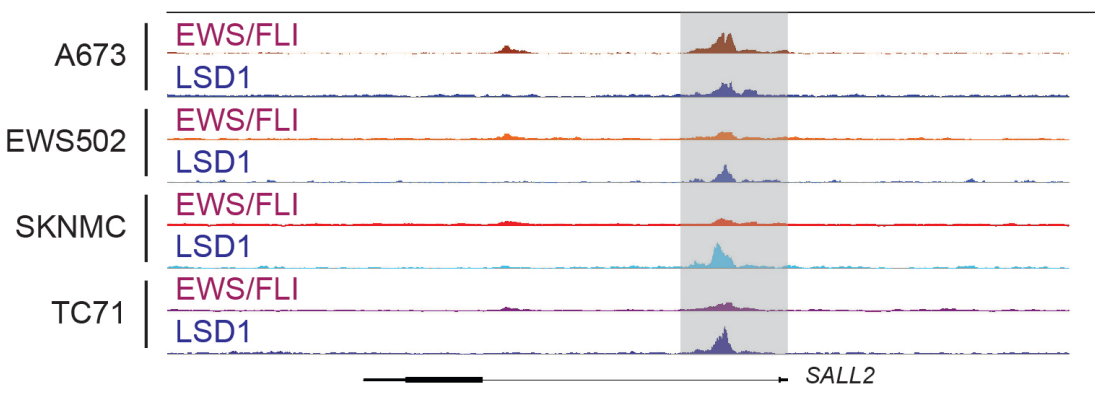

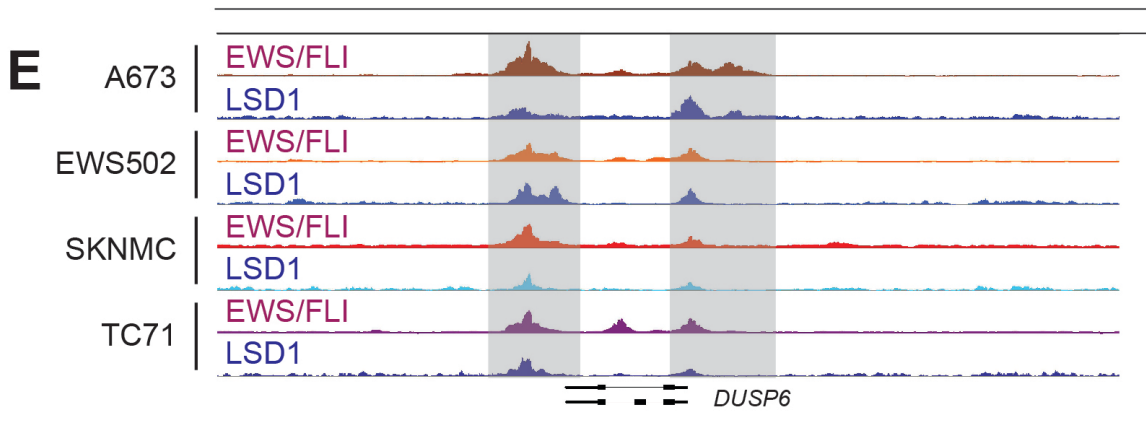


bioRxiv preprint doi: https://doi.org/10.1101/2020.05.05.079533; this version posted May 7, 2020. The copyright holder for this preprint (which was not certified by peer review) is the author/funder, who has granted bioRxiv a license to display the preprint in perpetuity. It is made available under aCC-BY-NC-ND 4.0 International license.

\section{Supplementary Figure 6}

A Genes proximal to EWS/FLI-LSD1 peaks

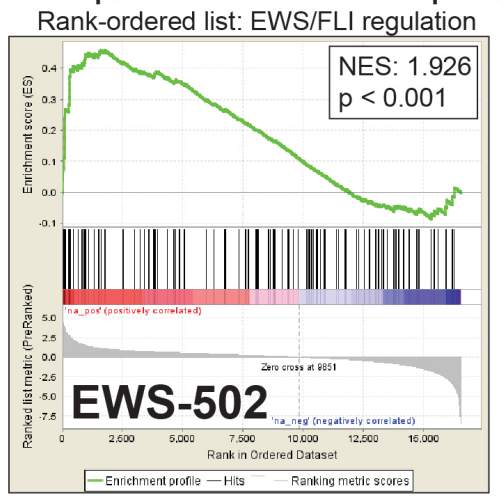

B Genes proximal to EWS/FLI-LSD1 peaks

Rank-ordered list: EWS/FLI regulation

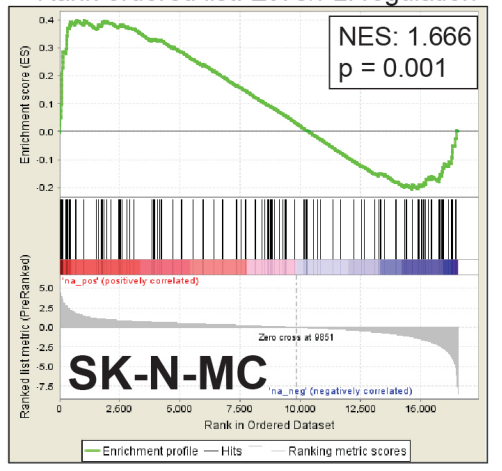

C Genes proximal to EWS/FLI-LSD1 peaks

Rank-ordered list: EWS/FLI regulation

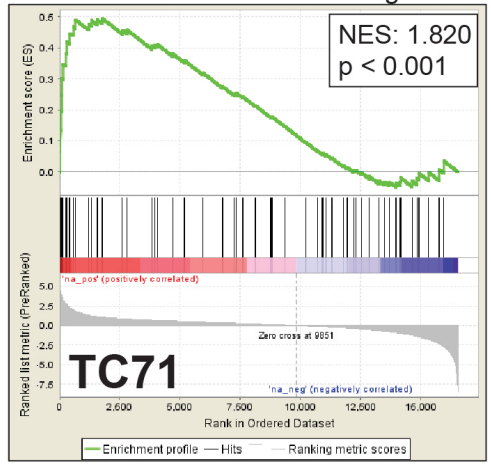

G

Genes proximal to EWS/FLI-LSD1 peaks

Rank-ordered list: EWS/FLI regulation

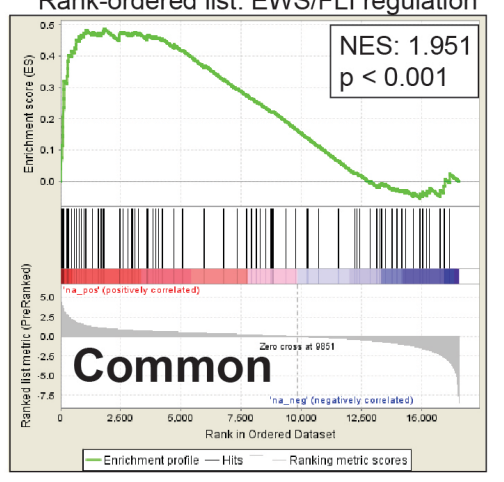

Genes proximal to EWS/FLI-LSD1 peaks Rank-ordered list: LSD1 regulation

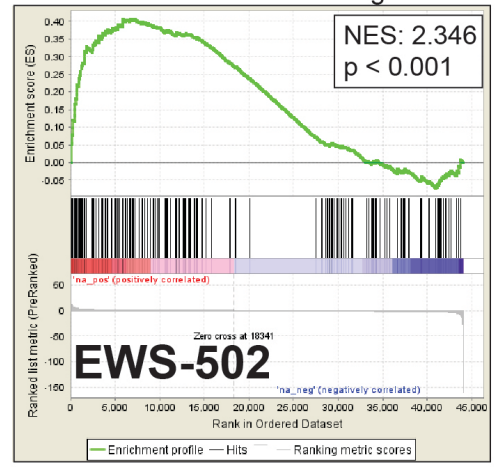

E Genes proximal to EWS/FLI-LSD1 peaks

Rank-ordered list: LSD1 regulation

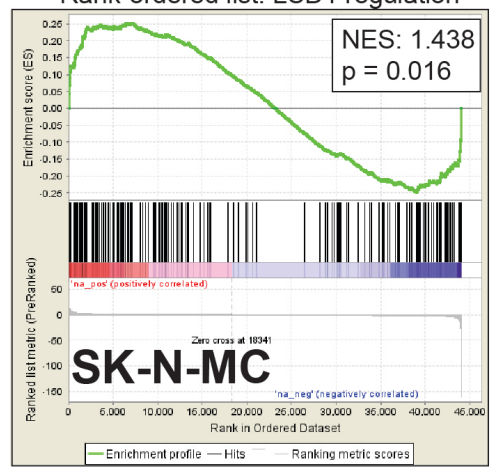

F Genes proximal to EWS/FLI-LSD1 peaks

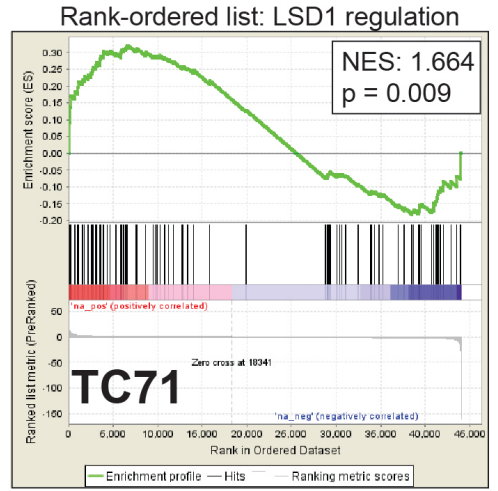

H Genes proximal to EWS/FLI-LSD1 peaks

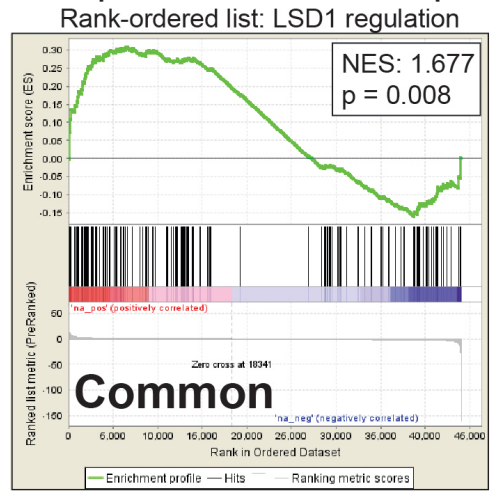


bioRxiv preprint doi: https//doi.org/10.1101/2020.05.05.079533; this version posted May 7, 2020. The copyright holder for this preprint (which

was not certified by peer review) is the author/funder, who has granted bioRxiv a license to display the preprint in perpetuity. It is made available under aCC-BY-NC-ND 4.0 International license.

\section{Supplementary Figure 7}

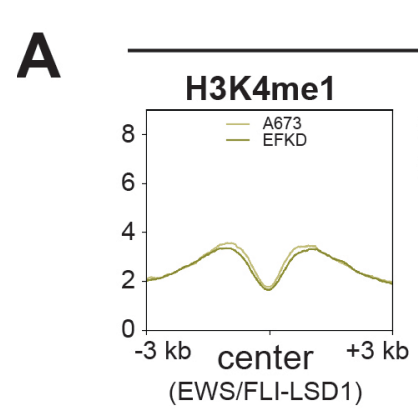

TSS-Proximal

B
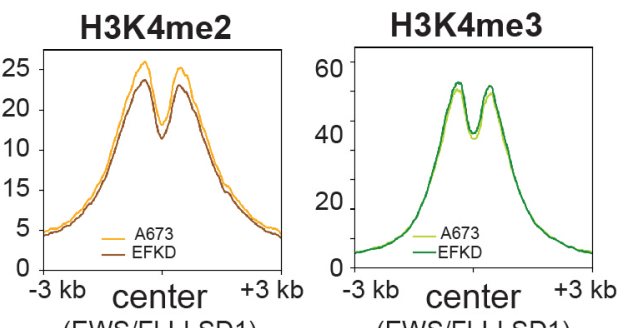

(EWS/FLI-LSD1)

(EWS/FLI-LSD1)

TSS-Distal

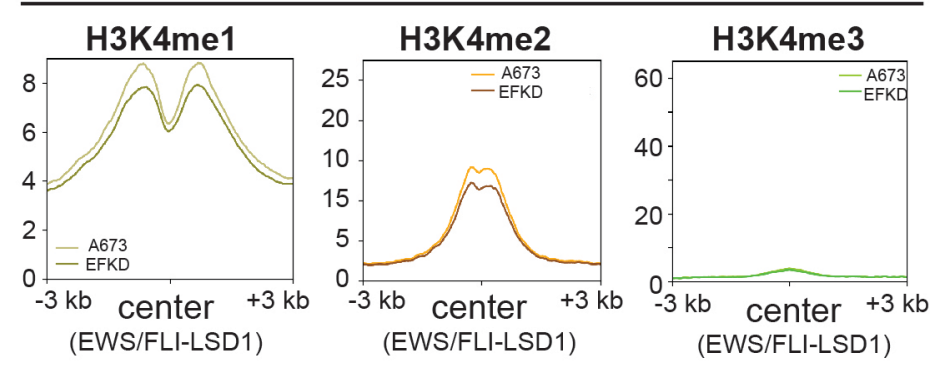

913 
bioRxiv preprint doi: https://doi.org/10.1101/2020.05.05.079533; this version posted May 7, 2020. The copyright holder for this preprint (which was not certified by peer review) is the author/funder, who has granted bioRxiv a license to display the preprint in perpetuity. It is made available under aCC-BY-NC-ND 4.0 International license.

\section{Supplementary Figure 8}

\section{A}

EWS-502
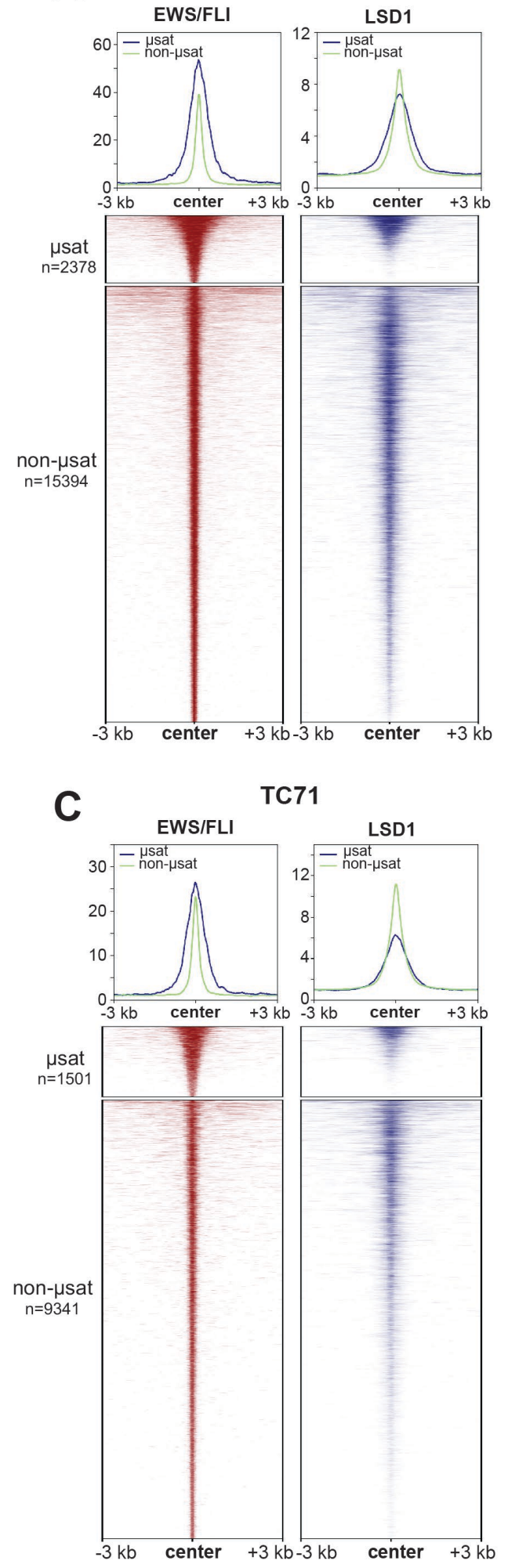

B

SK-N-MC
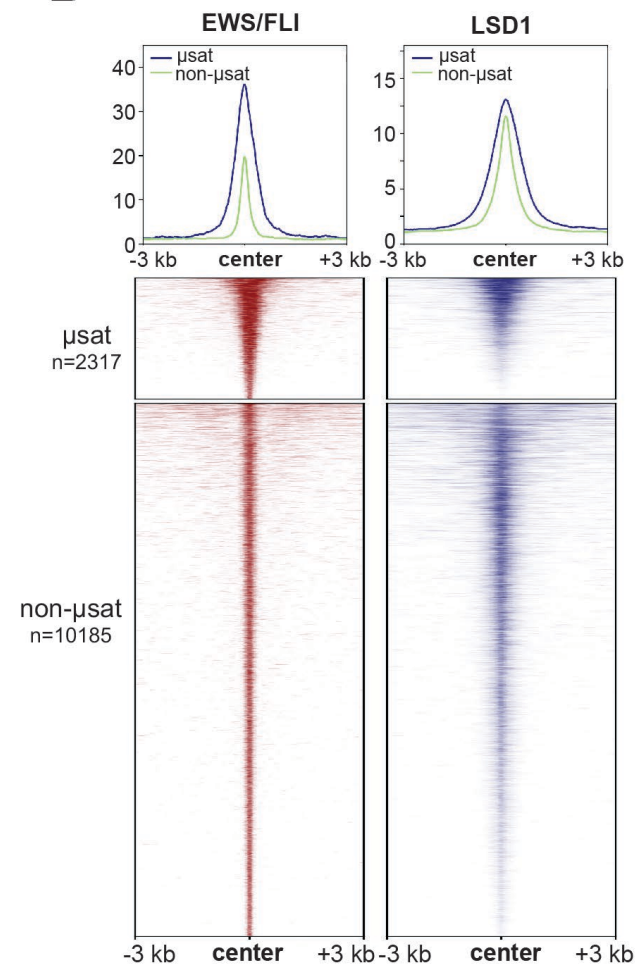

D

\section{EWS-502}

ETV2(ETS) p-value: 1E-536; HA site

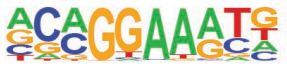

ZNF263 p-value: 1E-322 (EWS/FLI = alternative motif); $\boldsymbol{\mu}$ sat GAGGGAGGGAGGGAAGGAAG
AGAAAAAAGAAGAAGA

SK-N-MC

EWS:FLI p-value: 1E-891; HA site ACACGAAATE

EWSR1-FLI1 p-value: 1E-407; $\mu$ sat CGAGGAAGEAAGEAAGEAAG

TC71

ERG(ETS) p-value: 1E-490; HA site ACCGGAAGT

EWSR1-FLI1 p-value: 1E-228; $\boldsymbol{\mu s a t}$ AAAGGAGGAAGGAAGGAAGC 
Supplementary Figure 9; related to Supplementary Tables 1-6
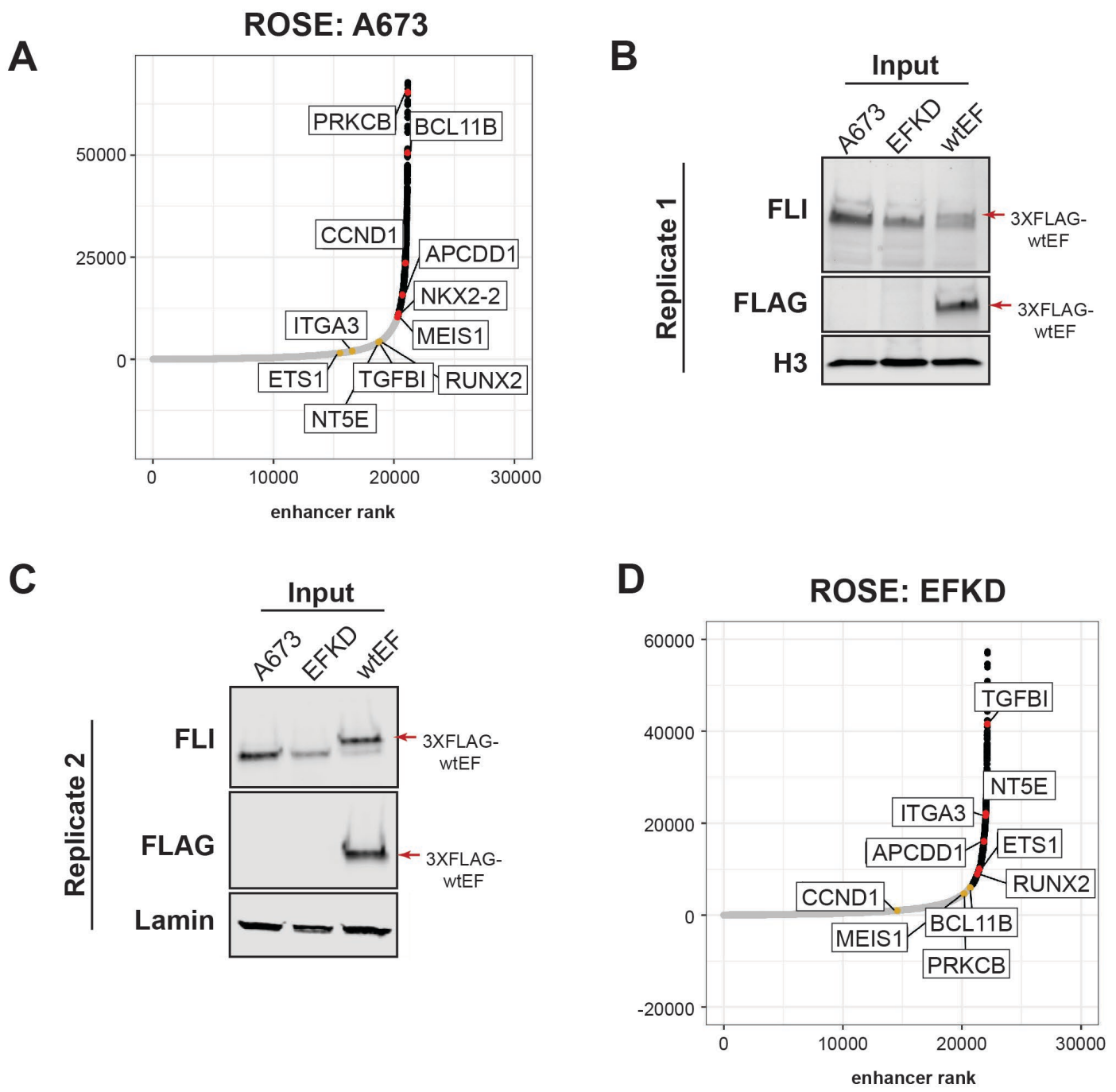

$\mathbf{E}$

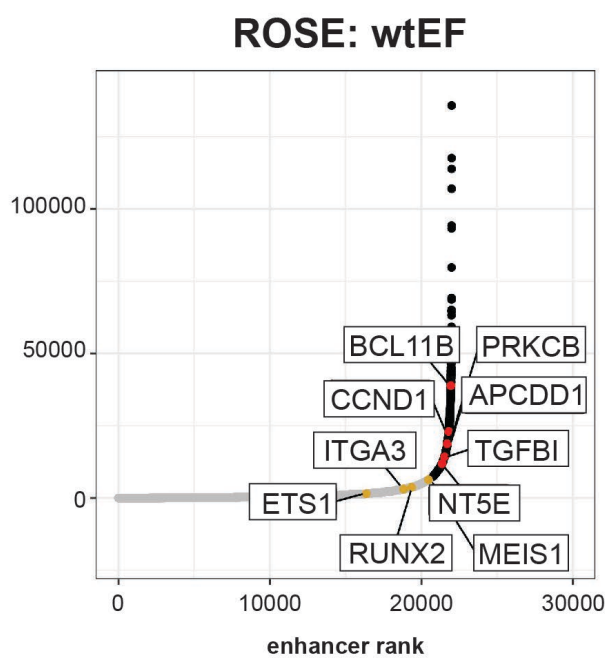

$\mathbf{F}$

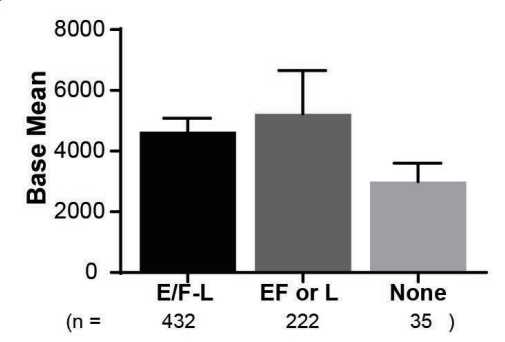




\section{Supplementary Figure 10; related to Supplementary Tables 7-14}

$A 673$

A

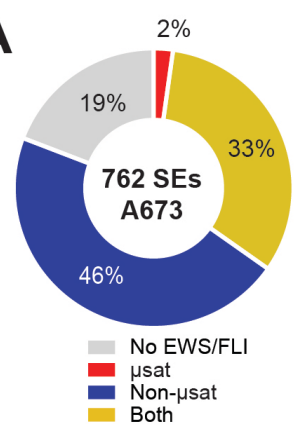

EWS-502

B

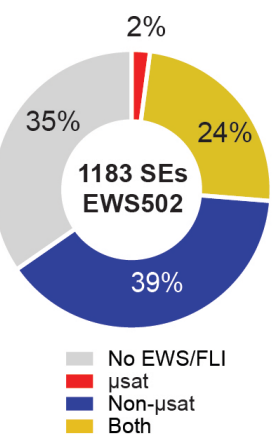

SK-N-MC
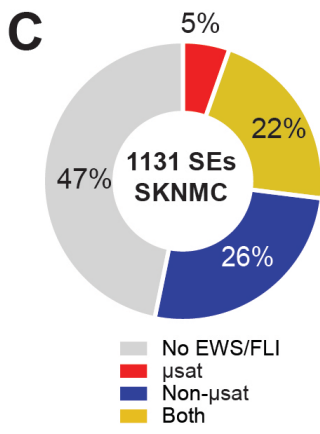

TC71

D

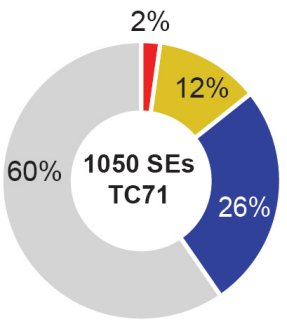

No EWS/FLI

- $\mu$ sat

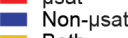
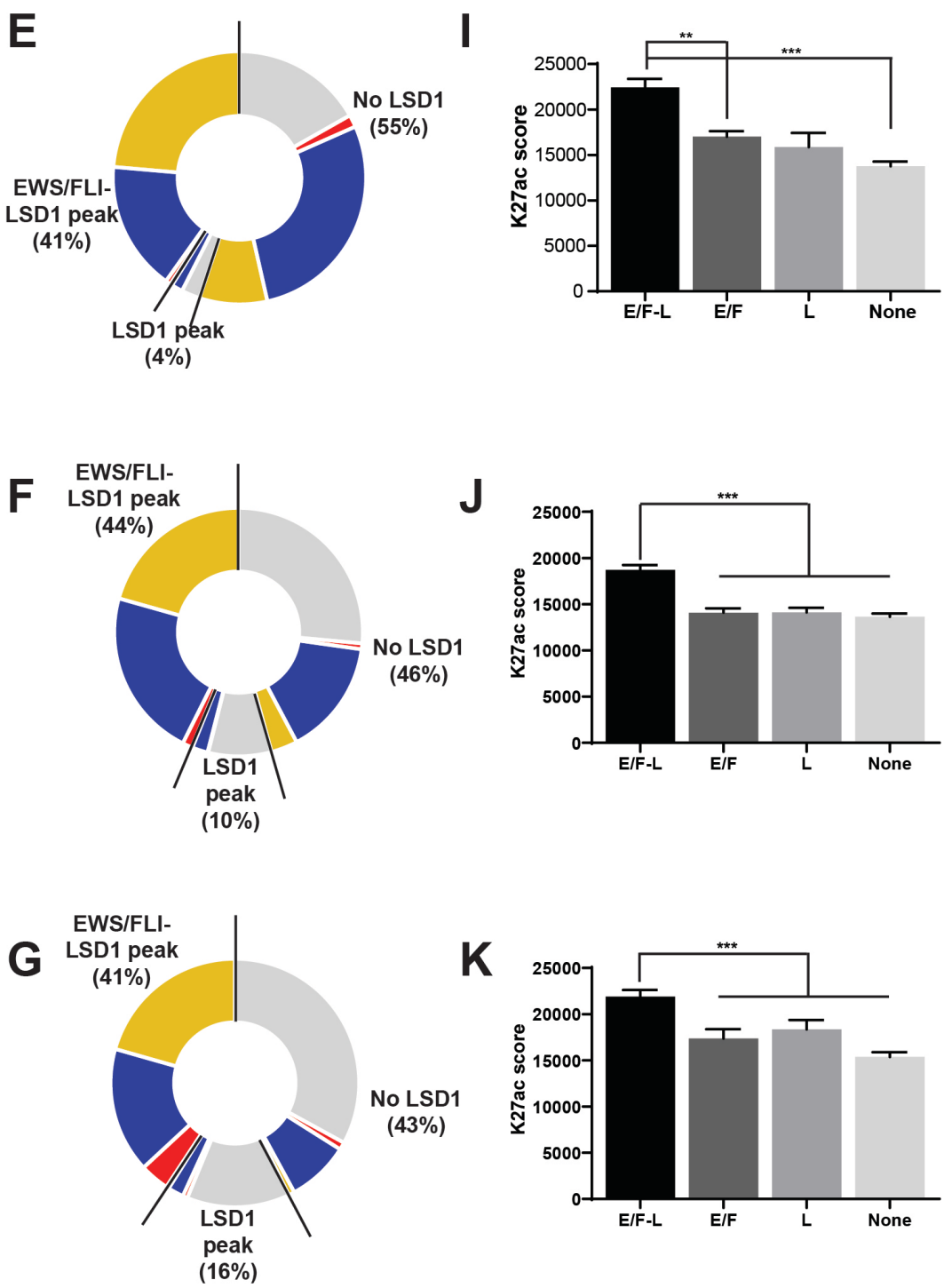

H

EWS/FLI-
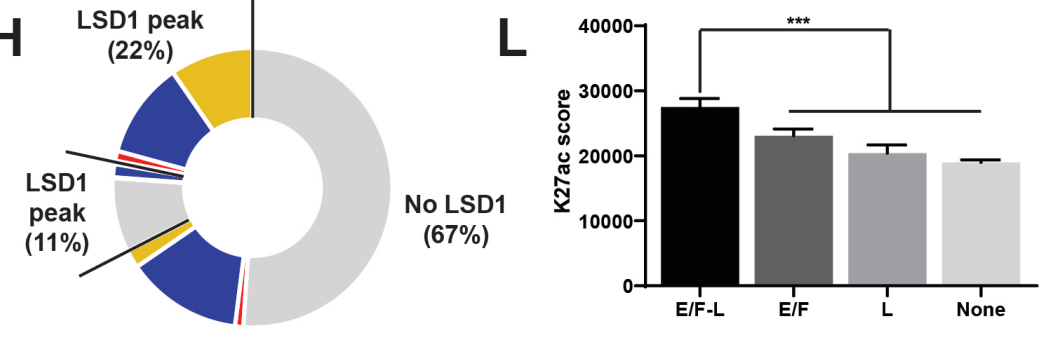


\section{Supplementary Figure 11; related to Supplementary Tables 8, 10, 12, and 14 .}

\section{A673}

A Genes proximal to EWS/FLI-LSD1 SEs Rank-ordered list: LSD1 regulation

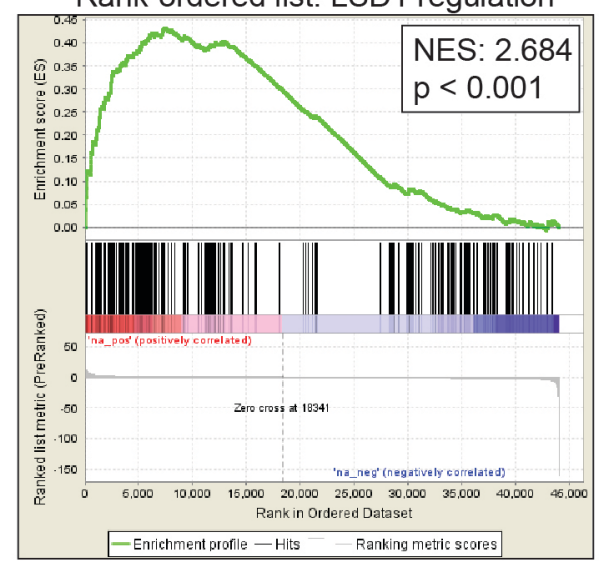

SK-N-MC

Genes proximal to EWS/FLI-LSD1 SES Rank-ordered list: LSD1 regulation

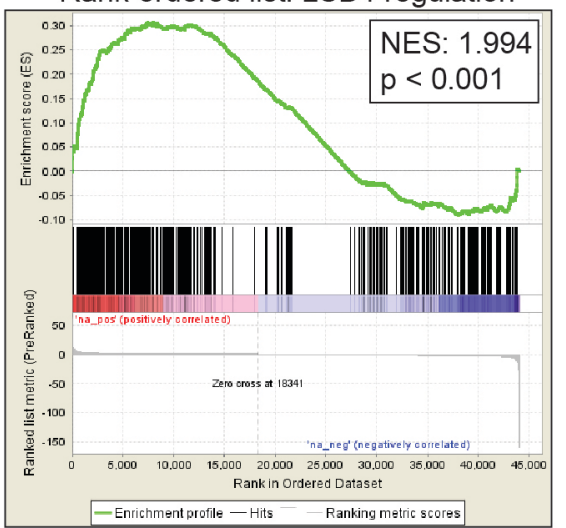

EWS-502

B Genes proximal to EWS/FLI-LSD1 SES Rank-ordered list: LSD1 regulation

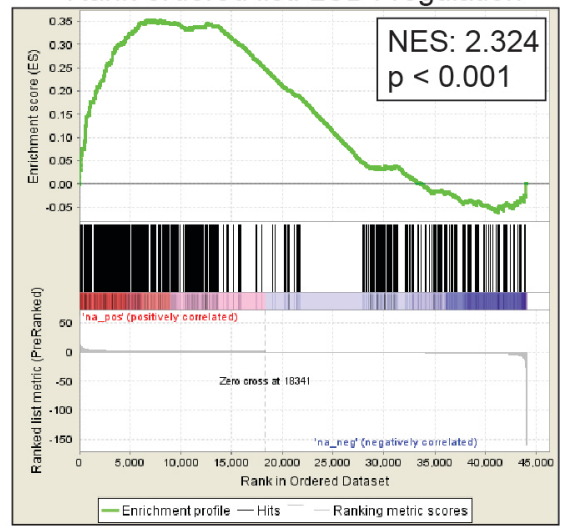

TC71

Denes proximal to EWS/FLI-LSD1 SEs Rank-ordered list: LSD1 regulation

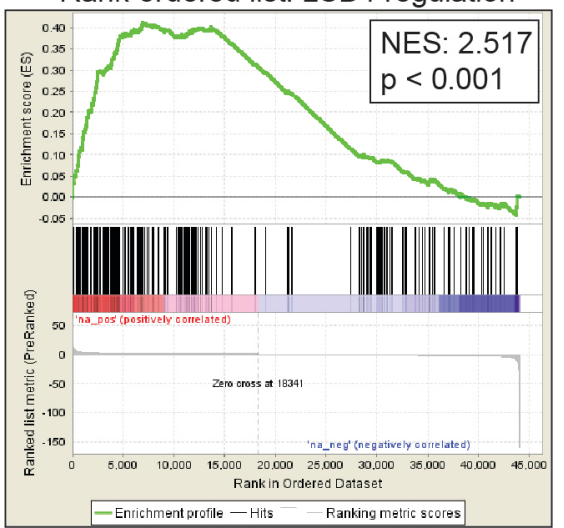


bioRxiv preprint doi: https://doi.org/10.1101/2020 05.05.079533; this version posted May 7,2020 . The copyright holder for this preprint (which was not certified by peer review) is the author/funder, who has granted bioRxiv a license to display the preprint in perpetuity. It is made available under aCC-BY-NC-ND 4.0 International license.

\section{Supplementary Figure 12}

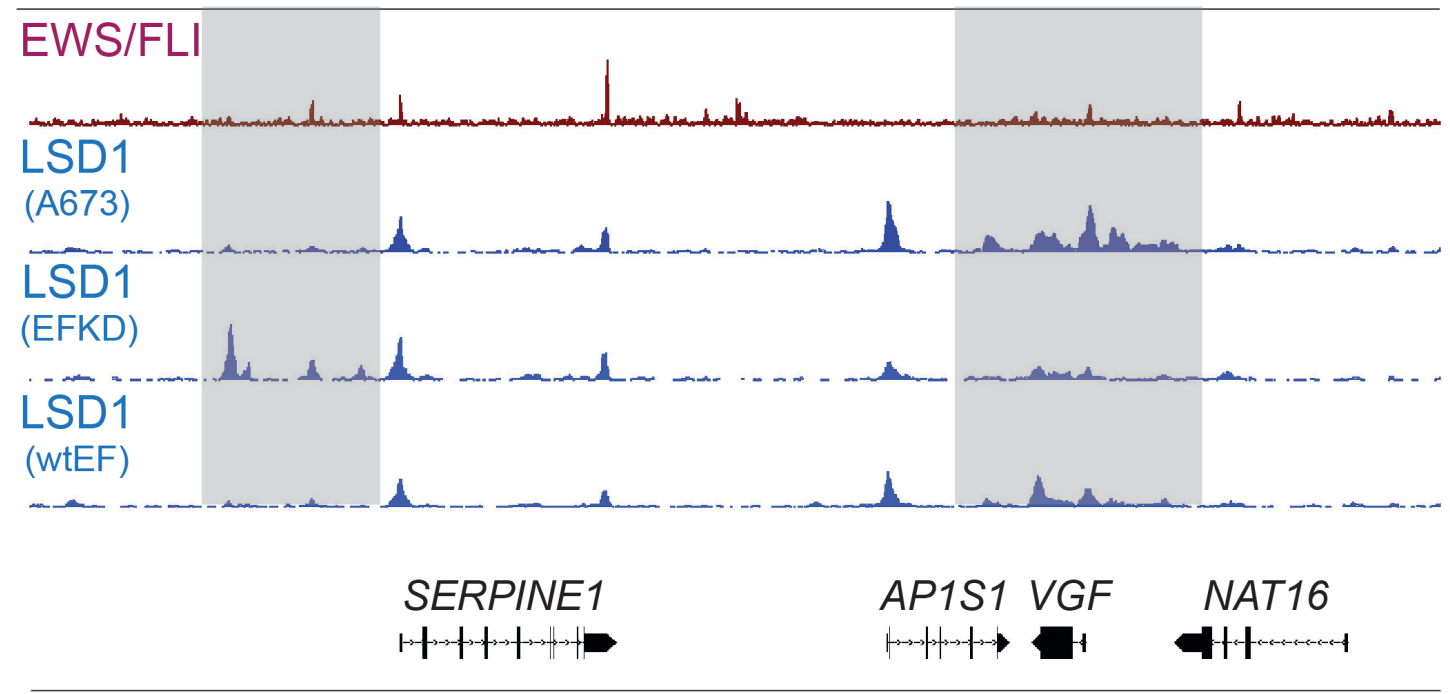


bioRxiv preprint doi: https://doi.org/10.1101/2020.05.05.079533; this version posted May 7, 2020. The copyright holder for this preprint (which was not certified by peer review) is the author/funder, who has granted bioRxiv a license to display the preprint in perpetuity. It is made available under aCC-BY-NC-ND 4.0 International license.

\section{Supplementary Figure 13; related to Supplementary Tables 15-20}

A

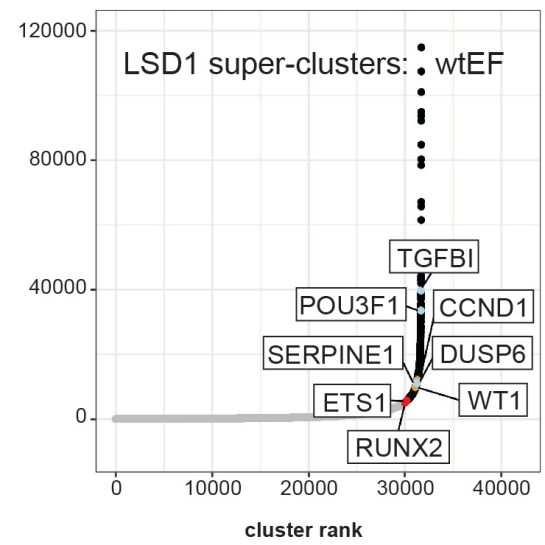

B

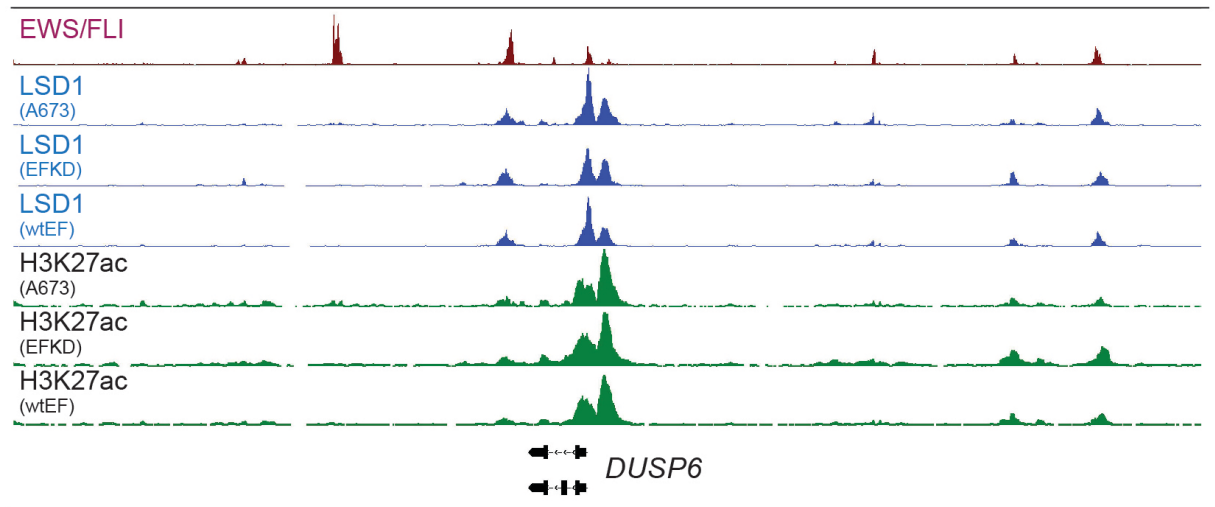

C $\overline{\text { EWS/FLI }}$

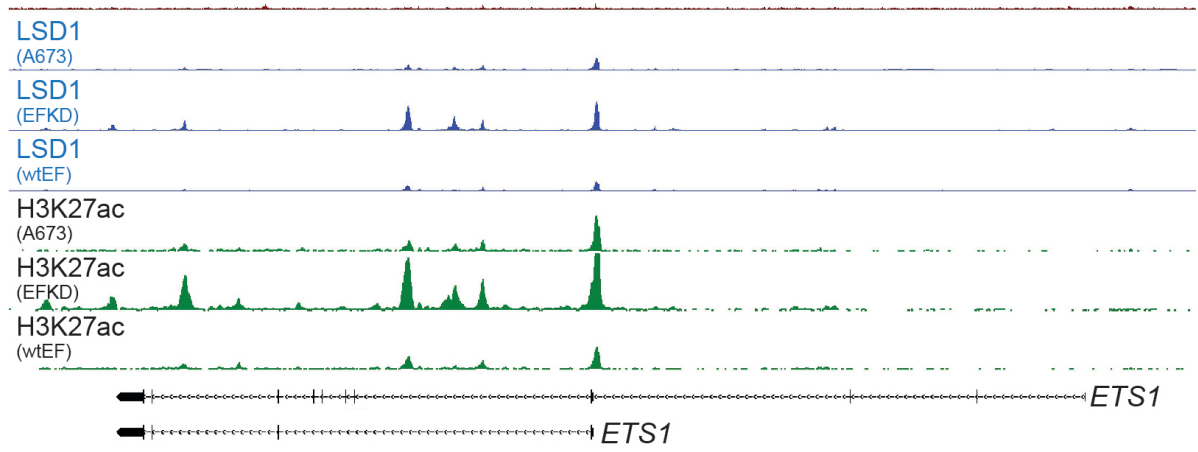

D EWS/FLI _

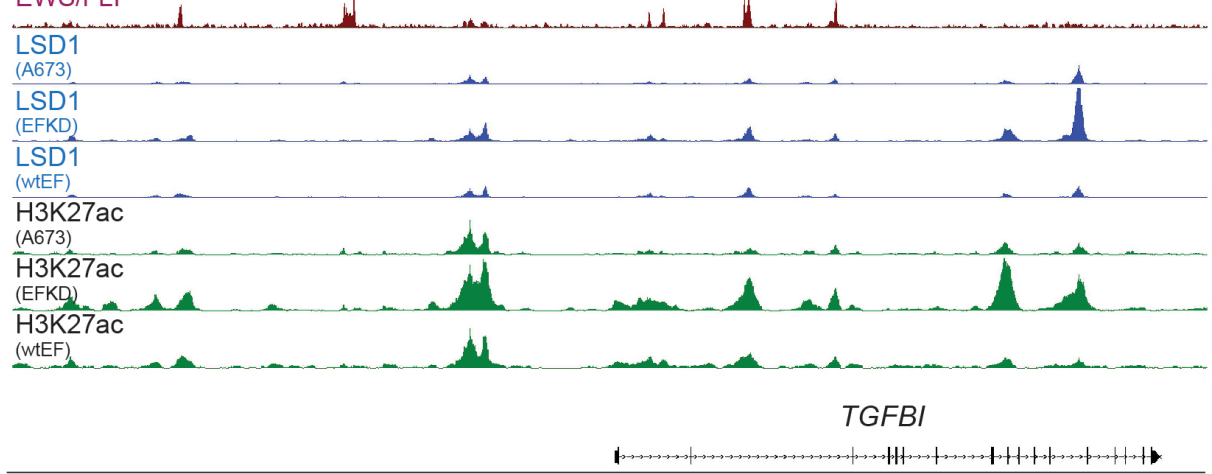




\section{Supplementary Figure 14; related to Supplementary Tables 2, 4, and 6.}

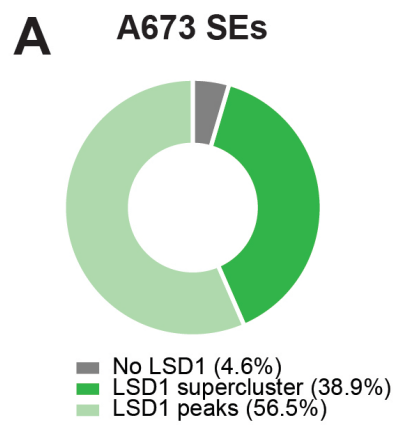

D

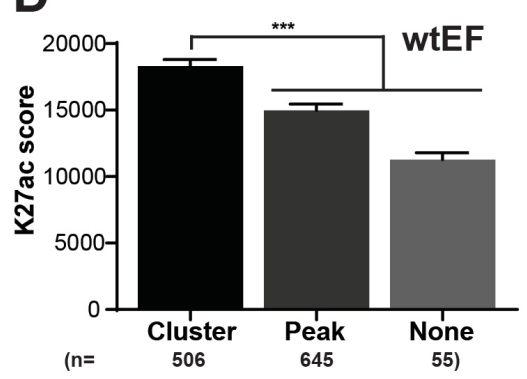

G

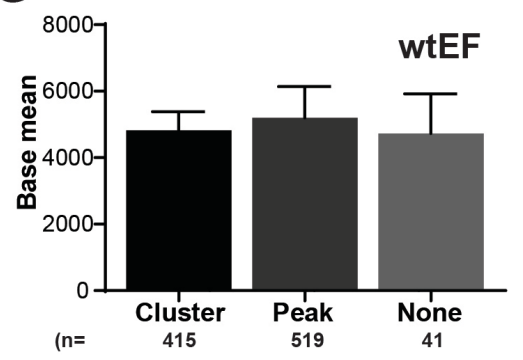

$J$
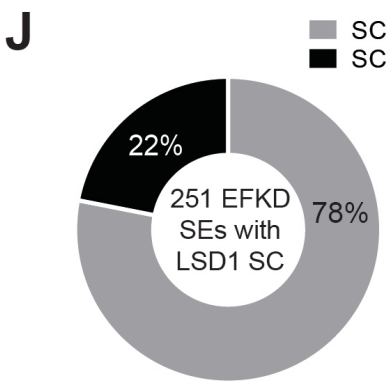

B WtEF SEs

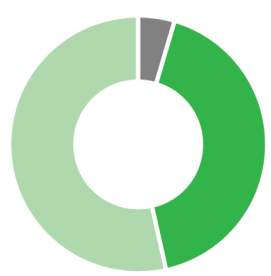

든.

- LSD1 supercluster $(42.0 \%)$

LSD1 peaks $(53.4 \%)$

E

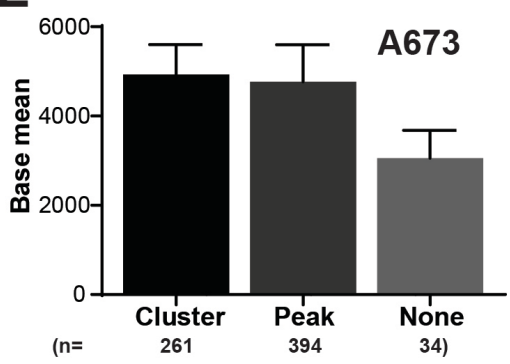

$\mathbf{F}$

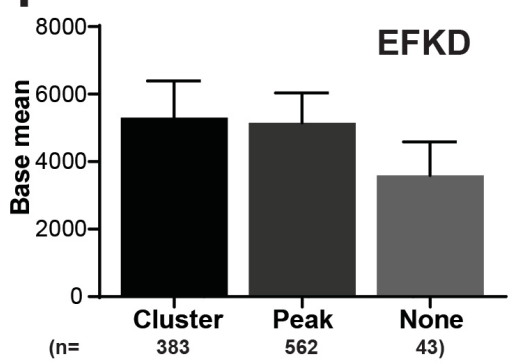

$\mathrm{H}$

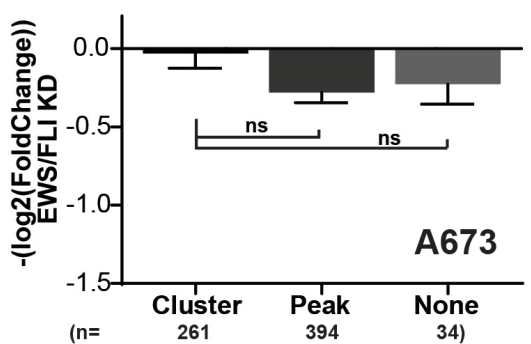

(n=

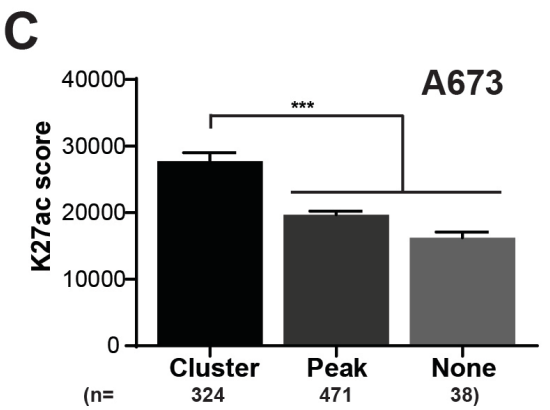

( $n=$
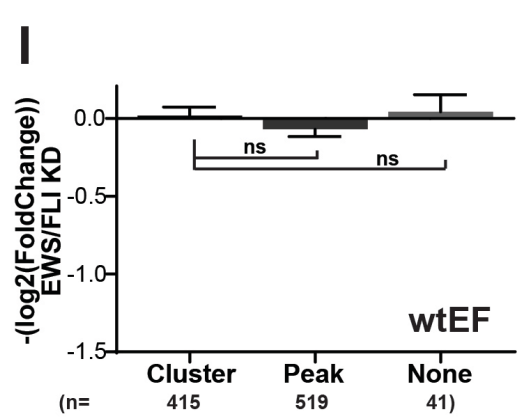


\section{SUPPLEMENTARY FILES}

929

930

931

932

933

934

935

936

937

938

939

940

941

942

943

944

945

946

947

948

949

950

951

952

953

Contains a list of key resources for the work performed in this report.

\section{Supplementary_File_1.xIsx}

Contains Supplementary Tables 1-20. annotated A673 superenhancers. The K27ac data used was generated by CUT\&Tag. annotated wtEF superenhancers. The K27ac data used was generated by CUT\&Tag. annotated A673 superenhancers. The K27ac data used was generated by CUT\&RUN.

Supplementary Tables 1-2: 1) Results of the ROSE analysis for superenhancers in A673 cells and 2)

Supplementary Tables 3-4: 3) Results of the ROSE analysis for superenhancers in EFKD cells and 4) annotated EFKD superenhancers. The K27ac data used was generated by CUT\&Tag.

Supplementary Tables 5-6: 5) Results of the ROSE analysis for superenhancers in wtEF cells and 6)

Supplementary Tables 7-8: 7) Results of the ROSE analysis for superenhancers in A673 cells and 8)

Supplementary Tables 9-10: 9) Results of the ROSE analysis for superenhancers in EWS-502 cells and 10) annotated EWS-502 superenhancers. The K27ac data used was generated by CUT\&RUN.

Supplementary Tables 11-12: 11) Results of the ROSE analysis for superenhancers in SK-N-MC cells and 12) annotated SK-N-MC superenhancers. The K27ac data used was generated by CUT\&RUN.

Supplementary Tables 13-14: 13) Results of the ROSE analysis for superenhancers in TC71 cells and 14) annotated TC71 superenhancers. The K27ac data used was generated by CUT\&RUN.

Supplementary Tables 15-16: 15) Results of the ROSE analysis for LSD1 superclusters in A673 cells and 16) annotated A673 LSD1 superclusters. The LSD1 data used was generated by CUT\&Tag.

Supplementary Tables 17-18: 17) Results of the ROSE analysis for LSD1 superclusters in EFKD cells and 18) annotated EFKD LSD1 superclusters. The LSD1 data used was generated by CUT\&Tag.

Supplementary Tables 19-20: 19) Results of the ROSE analysis for LSD1 superclusters in wtEF cells and 20) annotated wtEF LSD1 superclusters. The LSD1 data used was generated by CUT\&Tag. 